\title{
CLC-5 and KIF3B interact to facilitate CLC-5 plasma membrane expression, endocytosis, and microtubular transport: relevance to pathophysiology of Dent's disease
}

Anita A. C. Reed, Nellie Y. Loh, Sara Terryn, Jonathan D. Lippiat, Chris

Partridge, Juris Galvanovskis, Siân E. Williams, Francois Jouret, Fiona T. F. Wu, Pierre J. Courtoy, M. Andrew Nesbit, Patrik Rorsman, Olivier Devuyst, Frances M. Ashcroft and Rajesh V. Thakker

Am J Physiol Renal Physiol 298:F365-F380, 2010. First published 25 November 2009; doi:10.1152/ajprenal.00038.2009

You might find this additional info useful...

This article cites 62 articles, 38 of which can be accessed free at:

http://ajprenal.physiology.org/content/298/2/F365.full.html\#ref-list-1

This article has been cited by 3 other HighWire hosted articles

The posttranslational modification of tubulin undergoes a switch from detyrosination to acetylation as epithelial cells become polarized

Geraldine B. Quinones, Barbara A. Danowski, Anjan Devaraj, Vimla Singh and Lee A. Ligon

Mol. Biol. Cell, April 1, 2011; 22 (7): 1045-1057.

[Abstract] [Full Text] [PDF]

Endosomal Chloride-Proton Exchange Rather Than Chloride Conductance Is Crucial for

Renal Endocytosis

Gaia Novarino, Stefanie Weinert, Gesa Rickheit and Thomas J. Jentsch

Science, June 11, 2010; 328 (5984): 1398-1401.

[Abstract] [Full Text] [PDF]

Role of ClC-5 in Renal Endocytosis Is Unique among CIC Exchangers and Does Not Require PY-motif-dependent Ubiquitylation

Gesa Rickheit, Lena Wartosch, Sven Schaffer, Sandra M. Stobrawa, Gaia Novarino, Stefanie

Weinert and Thomas J. Jentsch

J. Biol. Chem., June 4, 2010; 285 (23): 17595-17603.

[Abstract] [Full Text] [PDF]

Updated information and services including high resolution figures, can be found at:

http://ajprenal.physiology.org/content/298/2/F365.full.html

Additional material and information about AJP - Renal Physiology can be found at:

http://www.the-aps.org/publications/ajprenal

This infomation is current as of December 20, 2011.

AJP - Renal Physiology publishes original manuscripts on a broad range of subjects relating to the kidney, urinary tract, and their respective cells and vasculature, as well as to the control of body fluid volume and composition. It is published 12 times a year (monthly) by the American Physiological Society, 9650 Rockville Pike, Bethesda MD 20814-3991. Copyright @ 2010 by the

American Physiological Society. ISSN: 0363-6127, ESSN: 1522-1466. Visit our website at http://www.the-aps.org/. 


\title{
CLC-5 and KIF3B interact to facilitate CLC-5 plasma membrane expression,
} endocytosis, and microtubular transport: relevance to pathophysiology of Dent's disease

\author{
Anita A. C. Reed, ${ }^{1 *}$ Nellie Y. Loh, ${ }^{1 *}$ Sara Terryn, ${ }^{2}$ Jonathan D. Lippiat, ${ }^{3}$ Chris Partridge, ${ }^{4}$ \\ Juris Galvanovskis, ${ }^{4}$ Siân E. Williams, ${ }^{1}$ Francois Jouret, ${ }^{2}$ Fiona T. F. Wu, ${ }^{1}{ }^{\text {Pierre J. Courtoy, }}{ }^{2}$ \\ M. Andrew Nesbit, ${ }^{1}$ Patrik Rorsman, ${ }^{4}$ Olivier Devuyst, ${ }^{2}$ Frances M. Ashcroft, ${ }^{5}$ and Rajesh V. Thakker ${ }^{1}$ \\ ${ }^{1}$ Academic Endocrine Unit and ${ }^{4}$ Diabetes Research Laboratories, Nuffield Department of Medicine, University of Oxford, \\ Oxford Centre for Diabetes, Endocrinology, and Metabolism, Churchill Hospital, Oxford; ${ }^{3}$ Institute of Membrane and Systems \\ Biology, Faculty of Biological Sciences, University of Leeds, Leeds; ${ }^{5}$ University Laboratory of Physiology, University of \\ Oxford, Oxford, United Kingdom; and ${ }^{2}$ Division of Nephrology and CELL Unit, de Duve Institute, Université Catholique de \\ Louvain Medical School, Brussels, Belgium
}

Submitted 23 January 2009; accepted in final form 20 November 2009

Reed AA, Loh NY, Terryn S, Lippiat JD, Partridge C, Galvanovskis J, Williams SE, Jouret F, Wu FT, Courtoy PJ, Nesbit MA, Rorsman P, Devuyst O, Ashcroft FM, Thakker RV. CLC-5 and KIF3B interact to facilitate CLC-5 plasma membrane expression, endocytosis, and microtubular transport: relevance to pathophysiology of Dent's disease. Am J Physiol Renal Physiol 298: F365-F380, 2010. First published November 25, 2009; doi:10.1152/ajprenal.00038.2009.-Renal tubular reabsorption is important for extracellular fluid homeostasis and much of this occurs via the receptor-mediated endocytic pathway. This pathway is disrupted in Dent's disease, an X-linked renal tubular disorder that is characterized by low-molecular-weight proteinuria, hypercalciuria, nephrolithiasis, and renal failure. Dent's disease is due to mutations of CLC-5, a chloride/proton antiporter, expressed in endosomes and apical membranes of renal tubules. Loss of CLC-5 function alters receptor-mediated endocytosis and trafficking of megalin and cubilin, although the underlying mechanisms remain to be elucidated. Here, we report that CLC-5 interacts with kinesin family member 3B (KIF3B), a heterotrimeric motor protein that facilitates fast anterograde translocation of membranous organelles. Using yeast two-hybrid, glutathione- $S$-transferase pull-down and coimmunoprecipitation assays, the $\mathrm{COOH}$ terminus of CLC-5 and the coiled-coil and globular domains of KIF3B were shown to interact. This was confirmed in vivo by endogenous coimmunoprecipitation of CLC-5 and KIF3B and codistribution with endosomal markers in mouse kidney fractions. Confocal live cell imaging in kidney cells further demonstrated association of CLC-5 and KIF3B, and transport of CLC-5-containing vesicles along KIF3B microtubules. KIF3B overexpression and underexpression, using siRNA, had reciprocal effects on whole cell chloride current amplitudes, CLC-5 cell surface expression, and endocytosis of albumin and transferrin. $\mathrm{Clcn}^{\mathrm{Y} /-}$ mouse kidneys and isolated proximal tubular polarized cells showed increased KIF3B expression, whose effects on albumin endocytosis were dependent on CLC-5 expression. Thus, the CLC-5 and KIF3B interaction is important for CLC-5 plasma membrane expression and for facilitating endocytosis and microtubular transport in the kidney.

chloride/proton antiporter; kinesin family; proximal tubular reabsorption; hypercalciuric nephrolithiasis; receptor-mediated endocytosis

THE RECEPTOR-MEDIATED ENDOCYTIC pathway (RMEP) plays an important role in facilitating renal tubular reabsorption and

* A. A. C. Reed and N. Y. Loh contributed equally to this work.

Address for reprint requests and other correspondence: R. V. Thakker, Academic Endocrine Unit, Nuffield Dept. of Medicine, Univ. of Oxford, Oxford Centre for Diabetes, Endocrinology, and Metabolism, Churchill Hospital, Oxford, OX3 7LJ, UK (e-mail: rajesh.thakker@ndm.ox.ac.uk). hence maintaining extracellular fluid homeostasis (4). This pathway is disrupted in Dent's disease (OMIM: 300009), an $\mathrm{X}$-linked renal tubular disorder characterized by low-molecular-weight proteinuria, hypercalciuria, nephrolithiasis, and progressive renal failure $(28,37)$. Dent's disease is usually caused by mutations in a chloride/proton antiporter, CLC-5 (GenBank accession number NM_001127899.1), and mice deleted for a Clcn5 allele develop the renal tubular defects associated with Dent's disease $(37,45,47,48,55)$.

CLC- 5 belongs to the nine-member family of CLC proteins (CLC-1 to CLC-7, CLC-Ka, and CLC-Kb), which include voltage-gated chloride channels and chloride/proton antiporters that are found at the plasma membrane and membranes of intracellular organelles. CLCs have diverse functions, which include the control of membrane excitability, the regulation of cell volume, and transepithelial transport (28). For example, CLC-5, which is an antiporter expressed at multiple sites in the human nephron, including the proximal tubules (PT), the thick ascending limb (TAL) of the loop of Henle, and the $\alpha$-intercalated cells of the collecting duct (CD), is involved in transepithelial solute transport (e.g., the RMEP of the PT cells) and is localized primarily in early endosomes and apical (luminal) membranes of renal PT $(7,16,49)$. Disruption of Clcn5 in mice leads to defective fluid-phase and receptor-mediated endocytosis, by the renal PT, indicating that CLC-5 contributes to endocytosis in vivo $(4,16,47,55)$. Indeed, the renal tubular abnormalities observed in patients with Dent's disease, which is caused by mutations in CLC-5, are consistent with a functional loss of CLC-5 in such reabsorptive pathways $(7,16)$. Furthermore, these renal abnormalities have been shown to result from altered receptor-mediated endocytosis in association with defective trafficking of the megalin and cubilin receptor complex (4).

The role of CLC-5 in endosomal trafficking remains to be established. Loss of CLC-5 function leads to impaired endosomal acidification which may contribute to the observed defects in endosomal trafficking (4). Interestingly, pharmacological inhibition of vacuolar acidification has been reported to decrease endosomal recycling and transfer to lysosomes (1) but not the rate of endocytosis, consistent with a trafficking defect $(6,52)$. Any possible role of CLC-5 in endosomal transport is likely to involve the CLC-5 $\mathrm{COOH}$ terminus (amino acids 551 to 746 ; Fig. $1 A$ ) as this has been shown to be cytoplasmic by 


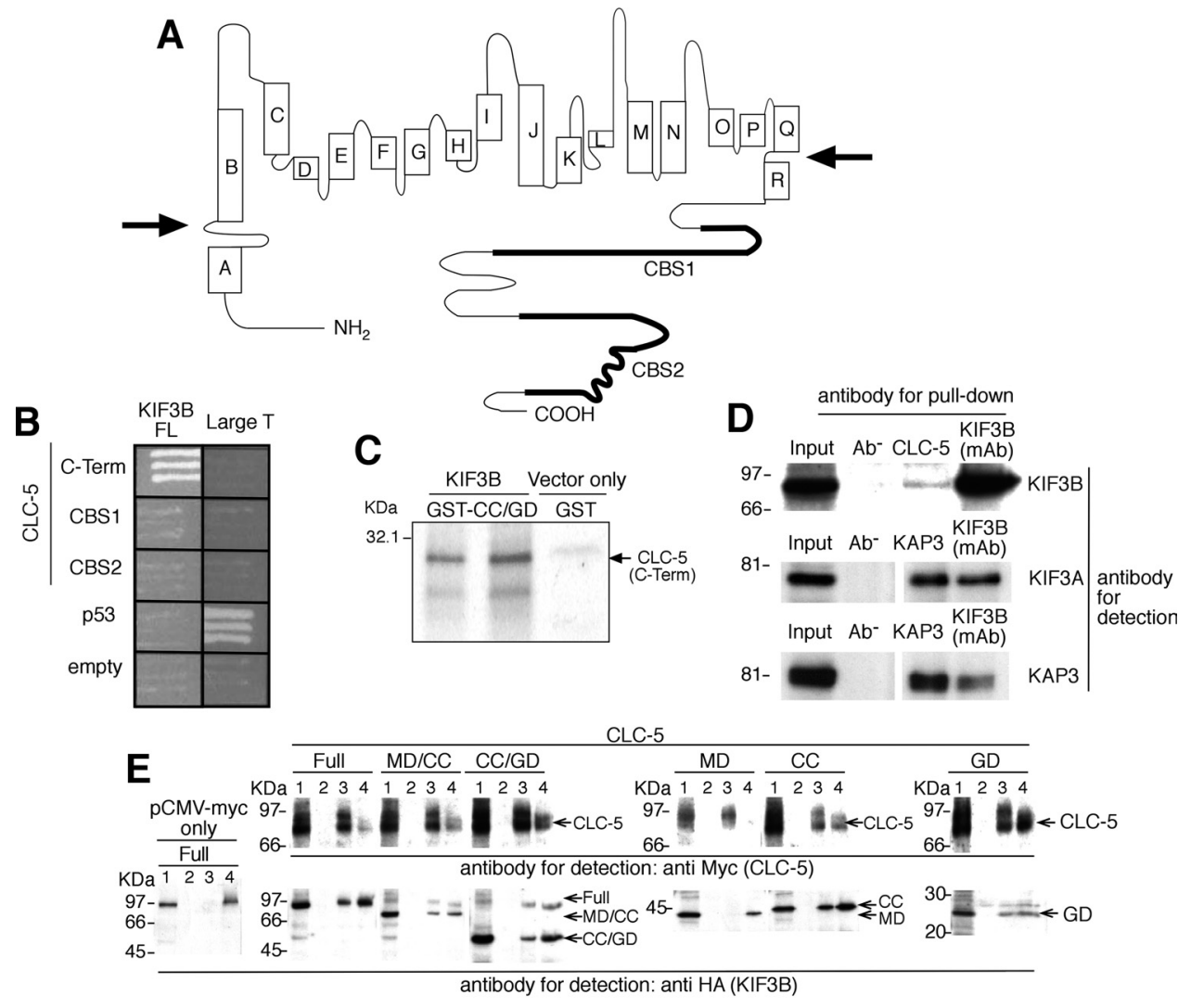

$\mathbf{F}$
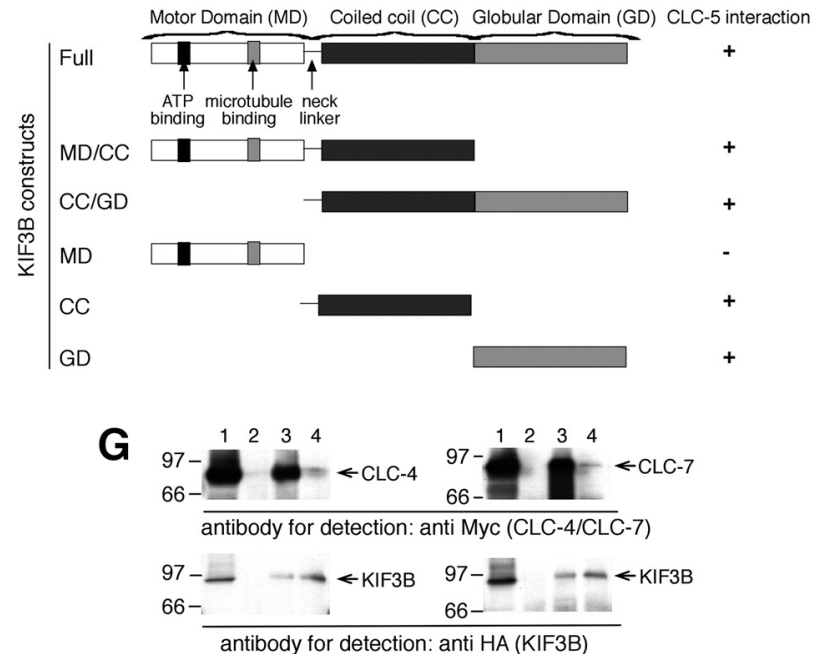

Fig. 1. Interactions between CLC-5 and KIF3B subunits. A: CLC-5 consists of 18 helices (A to $\mathrm{R}$ ) with the $\mathrm{NH}_{2}$ - and $\mathrm{COOH}$-terminus (C-term) domains being cytoplasmic (membrane boundaries indicated by arrows) (10,58). B: yeast 2-hybrid using the CLC-5 C-term, which contains 2 CBS domains (11) to screen a renal cDNA library, identified KIF3B as a putative interactor. Interaction between large T and $\mathrm{p} 53$ provided a positive control. $C:{ }^{35} \mathrm{~S}-\mathrm{methionine}-\mathrm{labeled} \mathrm{CLC}-5$ C-term was incubated with GST-tagged KIF3B coiled coil (CC)/globular domain (GD). Resin-bound proteins were resolved by SDS-PAGE and detected by autoradiography. Results from 2 independent in vitro translation experiments using 2 different GST-tagged KIF3B clones are shown. The larger band at $\sim 24.5$ $\mathrm{kDa}$ represents the 216 amino acid Myc-tagged CLC-5 C-term, whereas the smaller band at $\sim 18.5 \mathrm{kDa}$ likely represents another translated form of CLC-5 C-term that originated from use of an alternative methionine at codon 583 and hence lacked the $\mathrm{NH}_{2}$ terminal 32 amino acids. This smaller CLC-5 C-term, which was less efficiently translated, had both CBS domains and hence was pulled down by the GST-tagged KIF3B CC/GD. D: endogenous coimmunoprecipitation using wild-type mouse whole kidney extracts and a KIF3B monoclonal antibody (mAb). KIF3B, KIF3A, and KAP3 mAb were used to confirm endogenous coimmunoprecipitation of these proteins which form a trimeric complex. It is important to note that the interaction between CLC-5 and KIF3B is likely to be transient, as endosomes will be released to continue recycling, and that only a small proportion of the total cellular CLC-5 will be present, at a given time point, on the surface of endosomes that are being trafficked anterogradely; these features are consistent with the relatively low amount of KIF3B that is immunopreciptiated by CLC-5. E: coimmunoprecipitation studies using HEK293 cells demonstrated interactions between CLC-5 and KIF3B domains. Lane 1: input; lanes 2, 3, and 4: pull-down with no antibody, anti-Myc, or anti-HA antibodies, respectively. $F$ : summary of KIF3B domains showing presence (+) or absence (-) of interactions with CLC-5. G: coimmunoprecipitation studies using HEK293 cells demonstrated interactions between CLC-4 and KIF3B, and CLC-7 and KIF3B. Lane 1: input; lanes 2, 3, and 4: pull-down with no antibody, anti-Myc, or anti-HA antibodies, respectively. 
an analysis of the three-dimensional structures of homologous bacterial CLCs $(10,58)$. Moreover, the $\mathrm{COOH}$ terminus contains potential binding motifs for regulatory molecules: these include two cystathionine- $\beta$-synthase (CBS1 and CBS2) domains, a PY motif (PPLPPY), and a putative PDZ-binding motif $(11,25,49)$. Indeed, a number of proteins, including CLC-4, cofilin, WWP2, Nedd4-2, and $\mathrm{Na}^{+}-\mathrm{H}^{+}$exchanger regulatory factor 2 (NHERF2), have been reported to interact with CLC-5.

CLC-4, which is expressed in endosomes, contributes to endosomal acidification and trafficking by forming a complex with CLC-5 $(39,40)$. Cofilin, which is an actin depolymerizing protein, interacts with the $\mathrm{COOH}$ terminus of CLC-5, and phosphorylation of cofilin is associated with reduced albumin uptake (26). WWP2, which binds strongly to the PY motif of CLC-5, belongs to the same protein class as the ubiquitinprotein ligase Nedd4-2 that has also been demonstrated to interact with the $\mathrm{COOH}$ terminus of CLC-5 and to alter CLC-5 currents by decreasing the cell surface expression of CLC-5 $(24,46,49)$. CLC-5, whose cell surface expression increases in opossum kidney (OK) cells that are exposed to albumin, undergoes ubiquitination and a reduction in Nedd4-2 is accompanied by decreased albumin uptake in OK cells. These results indicate that Nedd4-2 may act via ubiquitination to shunt CLC-5 into the endocytic pathway (24). NHERF2, which is an epithelial PDZ scaffold that interacts with and alters the cell surface levels of CLC-5, links CLC-5 to ezrin and anchors the endocytic complex (23). However, the mechanisms whereby CLC-5 affects endosomal transport within the RMEP remain to be elucidated. We therefore used the CLC-5 COOH-terminus domain (Fig. 1A) as bait to perform a yeast two-hybrid screen of an adult human renal cDNA library with the aim of identifying interacting proteins involved in the endocytic pathway $(4,7)$.

\section{MATERIALS AND METHODS}

Yeast two-hybrid analysis. Partial CLC-5 cDNAs that encode the $\mathrm{COOH}$ terminus (C-term; peptides 551-746), CBS1 (peptides 576680), and CBS2 (peptides 674-746) were subcloned into pGBKT7, containing the Gal4 DNA binding domain (BD) to generate bait plasmids. Yeast strain PJ69-2A transformed with pGBKT7-CLC-5 (C-term) was used to screen a Matchmaker pretransformed adult human kidney cDNA library in Y187 yeast strain, according to the manufacturer's instructions (BD Bioscience) (42). The DNA sequences of prey plasmids isolated from positive clones were analyzed using a gapped BLAST search of NCBI databases. To confirm the interaction, prey plasmids were retransformed into PJ69-2A containing pGBKT7-CLC-5 (C-term) or pGBKT7 and tested for growth on selective plates (42). pGBKT7-p53 and pGADT7-Large T antigen were used as positive controls (42). KIF3B (FL) was subcloned into pACT2 containing the Gal4 activation domain. All inserts were confirmed by DNA sequence analysis (42). PJ69-2A was transformed sequentially with the appropriate CLC-5 and KIF3B constructs and monitored for growth on selective plates (42). Expression of CLC-5 and KIF3B Gal4 fusion proteins in yeast was confirmed by Western blot analysis using anti-HA (pACT2-KIF3B) or anti-Myc (pGBKT7CLC-5) antibodies (42).

Glutathione-S-transferase fusion protein and pull-down assay. KIF3B CC/GD was subcloned into pGEX-4T-1 and expressed in Escherichia coli BL21 (42). ${ }^{35}$ S-labeled CLC-5 (C-term) protein was prepared by in vitro transcription/translation using pGBKT7-CLC-5 (C-term; TNT System, Promega, Madison, WI). Glutathione-S-trans- ferase (GST)-pulldowns of GST-KIF3B and radiolabeled CLC-5 (C-term) proteins were performed as previously described (42).

Coimmunoprecipitations. Full-length CLC-5, CLC-4, CLC-7, and KIF3B, and five KIF3B deletional constructs (Fig. 1), were subcloned into pCMV-Myc and pCMV-HA, respectively (BD Bioscience), and cotransfected into HEK293 or COS7 cells using FuGene 6 (Roche) according to the manufacturer's instructions. Cells were harvested after $48 \mathrm{~h}$, and lysed in mRIPA (50 mM Tris $\cdot \mathrm{HCl}, \mathrm{pH} 7.4,150 \mathrm{mM}$ $\mathrm{NaCl}, 1 \mathrm{mM}$ EDTA, $0.05 \%$ SDS, $1 \%$ Triton X-100), and supplemented with protease inhibitors (COMPLETE, Roche) and coimmunoprecipitation was performed using anti-Myc or -HA antibodies. Protein complexes were captured with protein $\mathrm{G}$ sepharose beads, eluted with Laemmli buffer, and analyzed by Western blot using anti-Myc or HA antibodies as previously described (42). Endogenous coimmunoprecipitation of CLC-5 and KIF3B was investigated using a mouse whole kidney that was homogenized in mRIPA. Following incubation at $4^{\circ} \mathrm{C}$ for $3 \mathrm{~h}$, a supernatant fraction was obtained by centrifugation at $12,000 \mathrm{~g}$ for $10 \mathrm{~min}$ at $4^{\circ} \mathrm{C}$ and used to investigate for endogenous coimmunoprecipitation. To minimize nonspecific binding, the supernatant was preincubated for $1 \mathrm{~h}$ at $4^{\circ} \mathrm{C}$ with $50 \mu \mathrm{l}$ of protein $\mathrm{G}$ sepharose beads ( $50 \%$ slurry). After centrifugation at $12,000 \mathrm{~g}$ for $1 \mathrm{~min}$ at $4^{\circ} \mathrm{C}, 1 \mu \mathrm{g}$ of CLC-5 polyclonal antibody (7), KIF3B monoclonal antibody (BD Bioscience), or KAP3 monoclonal antibody (BD Bioscience) was added to the supernatant, and the sample was incubated overnight at $4^{\circ} \mathrm{C}$. Protein complexes were captured with protein $\mathrm{G}$ sepharose beads, eluted with Laemmli buffer, and analyzed by Western blot using KIF3B, KIF3A, and KAP3 monoclonal antibodies (BD Bioscience).

Confocal imaging. KIF3B (FL) was subcloned into pEGFP-C and CLC-5 (FL) with $\mathrm{NH}_{2}$ terminally tagged mRFP1 (monomeric red fluorescent protein) (3) was subcloned into pcDNA 3.1/Myc-His. HEK293 and/or COS7 cells were cotransfected with CLC-5 tagged with red fluorescent protein (RFP) and/or KIF3B-GFP constructs, using FuGene 6 (Roche). For Z-stack imaging, some CLC-5-RFP- and KIF3B-GFP-cotransfected HEK293 cells, 24 h posttransfection, were preextracted with a microtubule stabilizing buffer (MTSB; $80 \mathrm{mM}$ PIPES/KOH, pH 6.8, $1 \mathrm{mM} \mathrm{MgCl,} 5 \mathrm{mM}$ EGTA, and 0.5\% Triton $\mathrm{X}-100$ or $0.1 \%$ saponin) and fixed in $4 \%$ paraformaldehyde (PFA) or ice-cold methanol. CLC-5-Myc-transfected OK cells, 24 h posttransfection, and untransfected OK cells were preextracted with MTSB and fixed in 4\% PFA and coimmunostained using monoclonal anti-Myc (Santa Cruz Biotechnology) and rabbit polyclonal anti-ZO1 (Invitrogen) or monoclonal anti-MAPRE1 (EB1; AbCam), which immunostains the plus ends of microtubules (27), and rabbit polyclonal antiZO1 (Invitrogen), which immunostains tight junctions of polarized cells (27), and secondary antibodies anti-mouse Alexa Fluor 594 and anti-rabbit Alexa Fluor 488 (Molecular Probes). Some RFP-tagged CLC-5 cells, 24-h posttransfection, were fixed in $4 \%$ PFA and immunostained using monoclonal anti-Kinesin-2 (Covance) or monoclonal anti- $\alpha$-tubulin (Santa Cruz Biotechnology) and secondary antibody anti-mouse Alexa Fluor 488 (Molecular Probes). The Z stacks were recorded using a confocal laser-scanning microscope (Zeiss, LSM 10 META) with a Plan-Achromat $\times 63 / 1.4$ oil DIC objective (Carl Zeiss, Jena, Germany). An argon laser $\lambda=458 \mathrm{~nm}$ and $488 \mathrm{~nm}$ was used to excite enhanced green fluorescent protein (EGFP) and Alexa Fluor 488 fluorescence, respectively. The mRFP1 was visualized by a HeNe laser $\lambda=543 \mathrm{~nm}$. Emission of fluorescent proteins and Alexa Fluor 488 was detected in the Multitrack mode in META channels of the confocal system within the following spectral detection ranges: from 509 to $550 \mathrm{~nm}$ for EGFP, from 580 to $620 \mathrm{~nm}$ for mRFP1 and Alexa Fluor 594, and from 509 to $550 \mathrm{~nm}$ for Alexa Fluor 488. The Zeiss confocal microscope and software automatically generate a merged image from the original images obtained in the separate channels, thereby avoiding any errors or shifts that may arise from manual editing. Colocalization was assessed by using these merged images and by intensity profile line scans if there was a large variability in the intensity of the subcellular structures. Peaks obtained 
from intensity profile line scans were considered to overlap and hence indicate colocalization if the distance between them was $<300 \mathrm{~nm}$, which is the maximum approximate diameter of an endosomal vesicle in the proximal renal tubule (19). For live cell imaging, cells were observed $24 \mathrm{~h}$ posttransfection under a laser-scanning confocal microscope (Bio-Rad Radiance 2100) using a Nikon Fluor $\times 60$ water immersion objective lens. Cells were perfused with extracellular solution containing (in mM) $137 \mathrm{NaCl}, 5.6 \mathrm{KCl}, 1.2 \mathrm{MgCl}_{2}, 2.5$ $\mathrm{CaCl}_{2}$, and 5 HEPES $(\mathrm{pH} 7.4 \mathrm{NaOH})$ at $\sim+34^{\circ} \mathrm{C}$. HEK293 cells transfected with CLC-5-RFP and KIF3B-GFP were treated with nocodazole/DMSO $(20 \mu \mathrm{M} / 0.12 \%)$ or DMSO alone $(0.12 \%)$ for $4 \mathrm{~h}$ and fixed with $4 \%$ PFA. Microtubule restoration was verified by washing in nocodazole free medium (14). GFP was excited using a 488-nm Ar/Kr laser and detected with a 515- to 530-nm emission filter. mRFP1 was excited using a 543-nm green He-Ne laser and detected with a $600-\mathrm{nm}$ long pass filter. Simultaneous recordings were made using a 560-nm dichroic mirror. Live cell scans were sampled at $1 \mathrm{~Hz}$ using Lasersharp 2000 software (Bio-Rad Laboratories).

Electrophysiological studies. CLC-5 (FL) and KIF3B (FL) and deletional constructs (Fig. 1) were subcloned into pEGFP-C and pCMV-HA, respectively (BD Bioscience). The KIF3B-ATP construct was generated by using site-directed mutagenesis (Quikchange, Stratagene) to alter the ATP/GTP-binding site motif from GQTGTGKT to GQTGTAAT. HEK293 cells were transfected with CLC-5-GFP with or without KIF3B (FL)-HA, or a KIF3B deletion construct, using FuGene 6 (Roche). A threefold ratio of KIF3B to CLC-5 was used. In addition, cells were transiently transfected with pSUPER (24) containing a sequence for siRNA for KIF3B (GAAGCTACCAAGATCAACC; KIF3B siRNA) or an unrelated control (i.e., nonsense) sequence (control siRNA). The effects of the siRNA on protein expression were assessed by Western blot analysis performed with either an anti-KIF3B antibody (Santa Cruz Biotechnology), antiKIF3A antibody (BD Biosciences), or anti- $\alpha$-tubulin antibody (AbCam). Densitometry of the Western blots was performed using a GS-710 calibrated imaging densitometer and the Quantity One System Software (Bio-Rad Laboratories). Transfected cells were identified by EGFP epifluorescence. Patch pipettes were pulled from thinwalled borosilicate glass (Harvard) and fire-polished. Electrode resistances ranged from 1 to $3 \mathrm{M} \Omega$ in the experimental solutions. Currents were recorded using the whole cell patch-clamp configuration $(>70 \%$ series-resistance compensation) with an EPC-10 amplifier and Patchmaster software (HEKA). Currents were filtered at $10 \mathrm{kHz}$ and digitized at $50 \mathrm{kHz}$. Cells were held at $-30 \mathrm{mV}$ and $10-\mathrm{ms}$ pulses from -100 to $+200 \mathrm{mV}$ were applied at 1 -s intervals. A P/8 leak-subtraction protocol was used. The bath solution contained (in $\mathrm{mM}) 140 \mathrm{CsCl}, 1 \mathrm{CaCl}_{2}, 1 \mathrm{MgCl}_{2}, 10 \mathrm{HEPES}$, at $\mathrm{pH}$ 7.4. The pipette solution contained $42 \mathrm{CsCl}, 49 \mathrm{Cs}_{2} \mathrm{SO}_{4}, 10$ EGTA, $10 \mathrm{HEPES}$, at $\mathrm{pH}$ 7.4. Recordings were analyzed using Fitmaster (HEKA) and Microcal Origin 7.5 software. Conductance-voltage relationships were fitted with the Boltzmann equation, $G=G_{\max } /\left[1+\exp \left(V_{O .5}-V\right) / k\right]$, to obtain values for $G_{\max }$.

Cell surface expression of CLC-5. Cell surface proteins were biotinylated using an adaptation of a previously reported method (24). Briefly, HEK293 or OK cells were transfected with CLC-5-Myc and KIF3B-HA or siRNA constructs using FuGene 6 (Roche) or Lipofectamine Plus (Invitrogen), grown to confluence, and cell surface proteins were biotinylated with $1.22 \mathrm{mg} / \mathrm{ml}$ EZ-Link NHS-SS-Biotin (Pierce) at room temperature with gentle agitation. Monolayers were washed three times in cold phosphate-buffered saline, and the cells were lysed in mRIPA. The biotinylated proteins were isolated by binding to ImmunoPure immobilized Streptavidin (Pierce) for $1 \mathrm{~h}$ at $4^{\circ} \mathrm{C}$. The beads were pelleted and the supernatant that contained the cytosolic (unbiotinylated) fraction was recovered by centrifugation at $4,500 \mathrm{~g}$ for $6 \mathrm{~min}$ at $4^{\circ} \mathrm{C}$. The membrane (biotinylated) fraction was washed, and the pellet was resuspended in Laemmli sample buffer. Proteins from the cytosolic (unbiotinylated) and cell surface (biotinylated) fractions were resolved on SDS-polyacrylamide gel and trans- ferred to PVDF membrane and Western blot analysis was performed with an anti-Myc antibody (Santa Cruz Biotechnology). Densitometry of the Western blots was performed using a GS-710 calibrated imaging densitometer and the Quantity One System Software (BioRad Laboratories).

$R T-P C R$. PCR was performed on first-strand cDNA generated from total RNA of HEK293 cells, OK cells, human kidney (Ambion Europe), mouse kidney and mouse proximal renal tubular cells (mPTCs) using avian myeloblastosis virus RT and primers specific for cubilin, megalin, KIF3B, calmodulin, caveolin-1, caveolin-2, and GAPDH (primer sequences available on request), using methods previously described (42).

Albumin and transferrin uptake. Albumin and transferrin uptake were measured using modifications of standard methods, as previously described $(14,26)$. HEK293 or OK cells were seeded in 24-well plates and transiently transfected with empty vector or KIF3B (FL), MD/CC, CC/GD, -ATP or siRNA constructs using FuGene 6 (Roche) according to the manufacturer's protocol and grown for 4 or 7 days, respectively. To measure albumin uptake, cells were exposed to 50 $\mu \mathrm{g} / \mathrm{ml}$ of albumin conjugated to FITC, Alexa Fluor 594, or Texas Red (Sigma or Molecular Probes) for $120 \mathrm{~min}$. To measure transferrin uptake, OK cells were exposed to $50 \mu \mathrm{g} / \mathrm{ml}$ of transferrin conjugated to Alexa Fluor 594 (Molecular Probes) for $20 \mathrm{~min}$. Nonspecific binding was determined in cells exposed to albumin or transferrin for $1 \mathrm{~min}$. At the end of the uptake period, cells were washed in ice-cold HEPES buffer, pH 6, and solubilized in MOPS lysis buffer $(20 \mathrm{mM}$ MOPS, $0.1 \%$ Triton X-100, pH 7.4). The FITC, Texas Red, or Alexa Fluor 594 fluorescence was determined using a CytoFluor microplate reader (PerSeptive Biosystems) at 480-nm excitation and 520-nm emission or 596-nm excitation and 615-nm emission wavelengths, respectively. Total FITC/Texas Red-albumin or Alexa Fluor 594transferrin uptake was standardized to total cellular protein. For competition experiments, HEK293 and OK cells were simultaneously incubated with either $50 \mathrm{mg} / \mathrm{ml}$ unlabeled albumin or transferrin during the endocytosis assay, and the uptake of fluorescently labeled albumin or transferrin was compared with that without competition, which was the reference value set at $100 \%$.

Subcellular fractions from Clcn5 $5^{Y /-}$ kidneys. Mice were kept in accordance with approved protocols by the Ethics Committee for Animal Experimentation of the Université Catholique de Louvain Medical School (Brussels) (Ref. no. UCL/MD/2006/036). The Clcn $5^{\mathrm{Y} /-}$ mice, generated by targeted deletion of the exon VI of Clcn5, have been previously reported to have features of Dent's disease $(4,55)$. Kidneys from 15 -wk-old $C l c n 5^{\mathrm{Y} /+}$ and $C l c n 5^{\mathrm{Y} /-}$ male littermates were obtained. Subcellular fractions from these kidneys were prepared and used for Western blot analysis as previously reported (4). The samples were loaded as $20 \mu \mathrm{g}$ of total protein per lane, as appropriate for subcellular fractionations (13). The following antibodies were used: affinity-purified rabbit polyclonal antibodies against the $\mathrm{NH}_{2}$ terminus of human CLC-5 (55), mouse monoclonal antibodies against KIF3B (BD Bioscience), Rab5a (Santa Cruz Biotechnology), goat polyclonal antibodies against cathepsin D (Santa Cruz Biotechnology), mouse monoclonal antibodies (E11) against the E1 subunit of V-ATPase (Dr. S. Gluck, University of California, San Francisco, CA), and $\beta$-actin (Sigma, St. Louis, MO). Specificity was determined by incubation with nonimmune rabbit or mouse IgG (Vector Laboratories, Burlingame, CA). Densitometry analysis was performed with a Canon CanoScan8000F using the NIH Image V1.60 software.

mPTC primary cultures. Polarized and differentiated mPTC cultures were prepared as described previously (51). Kidneys from Clcn $5^{\mathrm{Y} /+}$ and $\mathrm{Clcn} 5^{\mathrm{Y} /-}$ mice aged 21-28 days were used to isolate tubules, which were seeded onto collagen-coated PTFE filter membranes in culture medium [DMEM:F12 with 15 mM HEPES, 0.55 $\mathrm{mM}$ Na-pyruvate, $0.1 \mathrm{ml} / \mathrm{l}$ nonessential amino acids, and the SingleQuots Kit (Lonza) containing hydrocortisone, hEGF, FBS, epinephrine, insulin, triiodothyronine, transferrin, gentamicin/amphotericin, 
$\mathrm{pH} 7.4$, and osmolality at $325 \mathrm{mosmol} / \mathrm{kgH}_{2} \mathrm{O}$ ] and incubated in a humidified chamber at $37^{\circ} \mathrm{C}$ and $5 \% \mathrm{CO}_{2}$. After 3-4 days, at $\sim 60-$ $80 \%$ confluency, primary cell cultures were transfected with an appropriate plasmid (1-2 $\mu \mathrm{g})$ using FuGene HD (Roche) or Lipofectamine (Invitrogen). After $72 \mathrm{~h}$, cells were analyzed by quantitative PCR (qPCR) for the expression of KIF3B (human and mouse) and KIF3A or an endocytosis assay was performed.

qPCR analyses. qPCR was performed as previously described (30). Total RNA from mouse kidney or mPTC primary cultures was extracted and reverse-transcribed into cDNA using SuperScript III RNase H Reverse Transcriptase (Invitrogen), using the following primers: KIF3B (154 bp) sense 5'-GCCAAAATCAAGGCCATGGAGAGT-3' and antisense 5'-GACTCTCCATTTGCTGCTGGATTTC-3', GAPDH (176 bp) sense 5' TGCACCACCAACTGCTTAGC-3' and antisense 5'-GGATGCAGGGATGATGTTCT-3'. qPCR analyses were performed in duplicate using the SYBR green fluorescence method, as previously reported (31). For each assay, standard curves were prepared by serial fourfold dilutions of mouse adult kidney cDNA. Calculations of primer efficiencies [efficiency $=\left(10^{-1 / \text { slope }}\right)-1$ ] demonstrated that KIF3B and GAPDH efficiencies were $0.92 \pm 0.04$ and $1.02 \pm 0.03$, respectively. mRNA expression was investigated in four or more pairs of $\mathrm{Clcn}^{\mathrm{Y} /+}$ and $\mathrm{Clcn} 5^{\mathrm{Y} /-}$ mouse kidneys, or $\mathrm{mPTC}$ primary cultures, after normalization to GAPDH: ratio $=2^{\mathrm{DCt}(\mathrm{KO}-\mathrm{WT}) \mathrm{KIF} 3 \mathrm{~B}} / 2^{\mathrm{DCt}(\mathrm{KO}-\mathrm{WT}) \mathrm{GAPDH}}(44)$.

Endocytosis assay using mPTC cultures. Mock or KIF3B-transfected mPTC cultures were washed with warm $\operatorname{HBSS}\left(37^{\circ} \mathrm{C}\right)$ after which they were incubated with FITC-conjugated bovine serum albumin at concentrations of $0.5 \mathrm{mg} / \mathrm{ml}$ for $15 \mathrm{~min}$ at $37^{\circ} \mathrm{C}$. After the incubation, mPTCs were washed five times with cold HBSS $\left(4^{\circ} \mathrm{C}\right)$ and lysis buffer was added. The fluorescence in the lysate was measured using a fluorimeter (Perkin Elmer) with excitation at $490 \pm 10 \mathrm{~nm}$ and emission at $525 \pm 10 \mathrm{~nm}$. Fluorescence was normalized for the amount of proteins in the primary cell cultures. Protein concentration was measured using the BCA kit. For metabolic inhibition experiments, mPTC cultures were incubated with $10 \mathrm{mM}$ sodium azide or 50 $\mathrm{mM}$ 2-deoxyglucose (DOG) for $30 \mathrm{~min}$ at $37^{\circ} \mathrm{C}$ before the endocytosis assay. For competition experiments, mPTC cultures were simultaneously incubated with $50 \mathrm{mM}$ unlabeled albumin or transferrin during the endocytosis assay.

Statistical analysis. Significance of differences was assessed by unpaired, two-tailed Student's $t$-test.

\section{RESULTS}

Yeast two-hybrid screen identifies KIF3B. Screening of an adult human kidney cDNA library with the $\mathrm{COOH}$ terminus of human CLC-5 (amino acids 551 to 746; Fig. 1A) as bait identified a clone (c73) that coded for a $\mathrm{COOH}$-terminal fragment (amino acids 410 to 747) of a member of the Kinesin superfamily, KIF3B (Fig. 1B) (21). KIF3B is a microtubule-dependent motor protein that exists in a heterotrimeric complex, known as Kinesin-2, with KIF3A (GenBank accession number NM_007054.5) and Kinesin Associated Protein 3 (KAP3; GenBank accession number NM_014970.2) $(5,35)$. KIF3B has an $\mathrm{NH}_{2}$-terminal motor domain (MD), a coiled-coil (CC) domain that dimerizes with that of KIF3A, and a $\mathrm{COOH}$-terminal globular domain (GD), that in conjunction with KIF3A-GD binds KAP3. KIF3B is coexpressed with KIF3A and KAP3 in the kidney, and the function of Kinesin-2 as a microtubule-based fast anterograde translocator of membranous organelles is consistent with a role for the KIF3B and CLC-5 interaction in endosomal trafficking (61).

Interaction between CLC-5 and KIF3B. To confirm that KIF3B and CLC-5 interact directly, we performed further yeast two-hybrid, GST pull-down, and coimmunoprecipitation studies with full-length (FL) and deletional constructs (Fig. 1, B-E). Coexpression of CLC-5 and KIF3B constructs in yeast cells was confirmed by Western blot analysis (data not shown). Yeast two-hybrid analysis showed that the CLC-5 COOH terminus and FL KIF3B interacted (Fig. 1B). However, CLC-5 CBS1 and CBS2 alone were not sufficient for the interaction with KIF3B (FL). The interaction between the CLC-5 COOH terminus and the $\mathrm{CC}$ and GD of KIF3B was confirmed by GST pulldown (Fig. 1C). In addition, the interaction between CLC-5 and KIF3B was established to occur in vivo, by demonstrating endogenous coimmunoprecipitation of the two proteins in mouse whole kidney extracts (Fig. 1D). KIF3B forms a Kinesin-2 complex, which consists of $\mathrm{KIF} 3 \mathrm{~A}, \mathrm{KIF} 3 \mathrm{~B}$, and $\mathrm{KAP} 3$ (5, 35), and this was confirmed to occur in the mouse whole kidney extracts by using appropriate KIF3A, KIF3B, and KAP3 antibodies to demonstrate endogenous coimmunoprecipitation (Fig. 1D). The structural basis of the CLC-5 and KIF3B interaction in mammalian cells was further investigated by cotransfecting human embryonic kidney (HEK293; Fig. 1E) and African green monkey kidney, COS7 cells (data not shown), with FL CLC-5 and KIF3B constructs that were tagged with Myc and HA epitopes, respectively. When Myc-CLC-5 was immunoprecipitated with anti-Myc antibody, the immunoreactive band of KIF3B was detected in the immunoprecipitate. Myc-CLC-5 was reciprocally coimmunoprecipitated with anti-HA antibody. The use of KIF3B deletion constructs containing the $\mathrm{MD}, \mathrm{CC}$, or GD alone or in combination $\mathrm{MD} / \mathrm{CC}$ and $\mathrm{CC} / \mathrm{GD}$ ) demonstrated that the KIF3B CC and GD could interact individually or as a fusion protein with CLC-5 (Fig. 1, E and F). These results establish an interaction, in mammalian cells, between the CLC-5 COOH terminus and the fused CC and GD of KIF3B. The COOH terminus and the CBS domains of CLCs are highly conserved (11) and to assess the specificity of this interaction, the interactions between KIF3B and two other CLCs, CLC-4 and CLC-7, were therefore investigated. CLC-4 and CLC-7 were selected because one of them, CLC-4, has a $\mathrm{COOH}$ terminus that is highly conserved with an amino acid identity of $73 \%$ and a similarity of $87 \%$ (BlastP) to that of the CLC-5 COOH terminus, and CLC-7 has a $\mathrm{COOH}$ terminus that is less highly conserved with a $27 \%$ identity and $49 \%$ similarity to that of the CLC-5 COOH terminus. However, CLC-4 has a predominant role in epithelial endosomal transport (40), whereas CLC-7 has a predominant role in osteoclast late endosomal and lysosomal transport (28). The interaction between KIF3B and CLC-4 and CLC-7 was investigated by cotransfection of Myc-CLC-4 or Myc-CLC-7 with HA-KIF3B in HEK293 cells (Fig. 1G). KIF3B was detected in immunoprecipitates from both Myc-CLC-4- and Myc-CLC-7-transfected cells when immunoprecipitated with antiMyc antibody. Both Myc-CLC-4 and Myc-CLC-7 were reciprocally immunoprecipitated with anti-HA antibody. These findings indicate that there is a potential common trafficking mechanism involving KIF3B and the $\mathrm{COOH}$ terminus of other members of the CLC family.

CLC-5-containing vesicles are transported along KIF3B microtubules. The basis of the CLC-5 and KIF3B interaction, in mammalian cells, was further investigated by colocalization studies of CLC-5 and KIF3B using transient expression of fluorescently tagged CLC-5 and KIF3B in HEK293 and COS7 (data not shown) cells. This revealed KIF3B to be mostly distributed in a punctate pattern throughout the cytoplasm (Fig. 2A). KIF3B also associated with tubulin (data not shown), and this microtubulelike distribution and colocalization with tubulin are consistent 
A

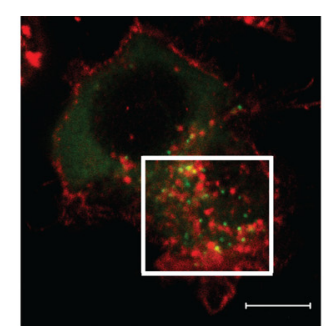

B
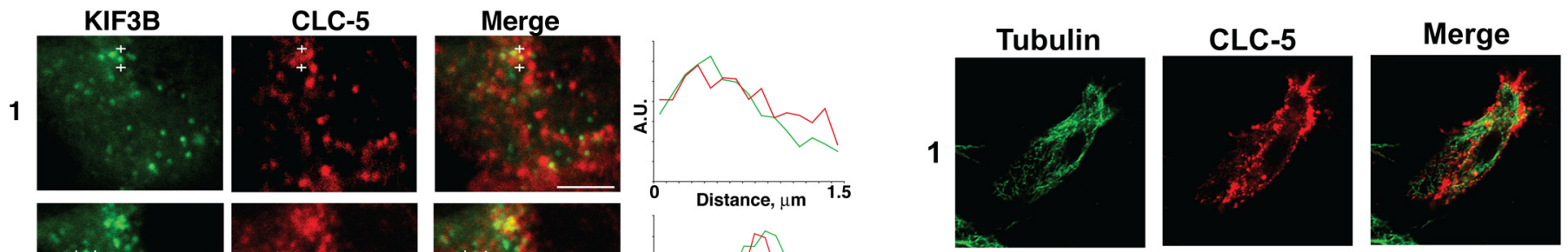

2
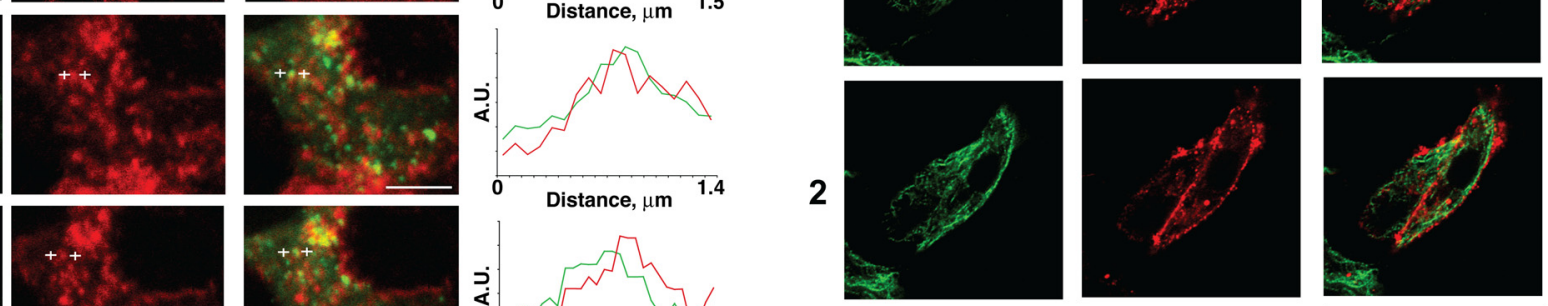

3
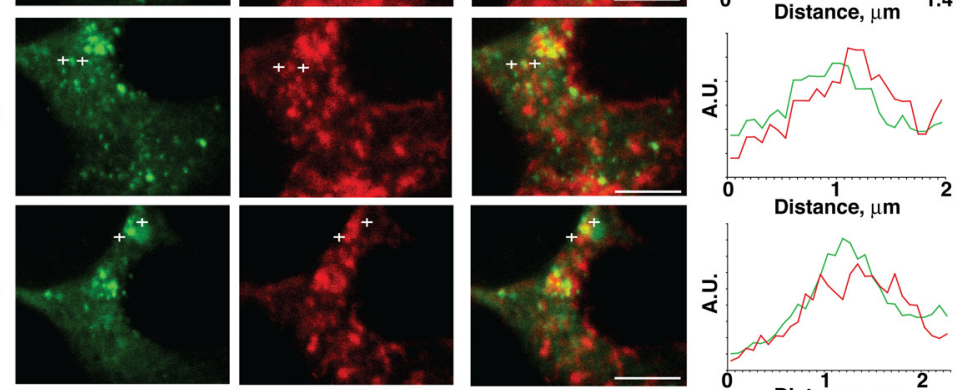

4
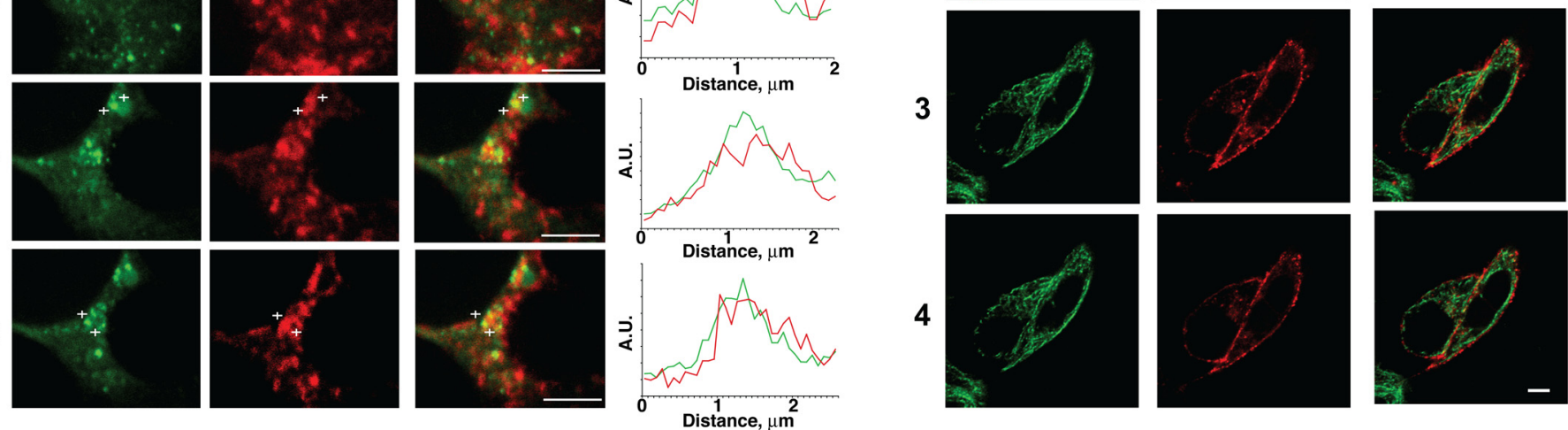

5

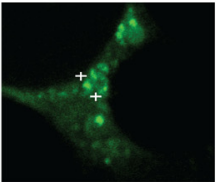

Fig. 2. Confocal microscopy shows colocalization of CLC-5 and KIF3B. HEK293 cells transfected with fluorescently tagged CLC-5 and KIF3B (CLC-5-RFP and KIF3B-GFP) and costained with anti- $\alpha$-tubulin or anti-Kinesin-2. A-C: Z-stack dual wavelength confocal microscopy. For each stack, images were obtained in 2 channels over 15 horizontal planes that were $0.7 \mu \mathrm{m}$ apart. A: HEK293 cells transfected with KIF3B-GFP and CLC-5-RFP. Green signals: KIF3B; red signals: CLC-5; yellow signals: colocalized KIF3B and CLC-5 (merge). Confocal Z-stack images and intensity profile line scans demonstrated that KIF3B-GFP and CLC-5-RFP are partially colocalized, as evidenced by the yellow signals or by an overlap of $<300 \mathrm{~nm}$, which is the estimated diameter of a proximal tubular endosomal vesicle (19), in the red and green peaks (confocal images 1 to 5). The intensity profile line scans were performed between the white crosses as indicated on confocal images 1 to 5, with the intensity measured in arbitrary units (A.U.). Scale bar top: $10 \mu \mathrm{m}$; scale bar confocal images 1 to 5: $2 \mu \mathrm{m}$. B: HEK293 cells transfected with CLC-5-RFP and costained with anti- $\alpha$-tubulin. Red signals: CLC-5; green signals: tubulin; yellow signals: colocalized CLC-5 and tubulin (merge). CLC-5-RFP was present at the plasma membrane and in punctate structures throughout the cytoplasm, where it was localized with tubulin, indicating its association with microtubules. Scale bars: $10 \mu \mathrm{m}$. C: HEK293 cells transfected with CLC-5-RFP and costained with anti-Kinesin-2 antibody. Red signals: CLC-5; green signals: Kinesin-2; yellow signals: colocalized CLC-5 and Kinesin-2 (merge). Scale bars: $10 \mu \mathrm{m}$. $D$ and $E$ : live cell imaging using dual-wavelength confocal microscopy of HEK293 cells cotransfected with full-length CLC-5-RFP and full-length KIF3B-GFP. Green signals: KIF3B; red signals: CLC-5; yellow signals: colocalized CLC-5 and KIF3B. Scale bar: $10 \mu \mathrm{m}$. A proportion of CLC-5-RFP-labeled vesicles was transported along KIF3B-labeled cytoskeletal network structures. $E$ : progress of a vesicle (arrowed), over $10 \mathrm{~s}$, is illustrated. The vesicles were estimated to move at an approximate rate of $0.42 \mu \mathrm{m} / \mathrm{s}$. Scale bar: $5 \mu \mathrm{m}$.

with its presence on microtubules (61). CLC-5 was concentrated at the plasma membrane, and in punctate structures throughout the cytoplasm, where it showed partial colocalization with KIF3B (Fig. 2A). A detailed examination using intensity profile line scan analysis in five cells helped to further demonstrate the colocalization of CLC-5 and KIF3B. Thus, an examination of 138 vesicles revealed that 68 vesicles expressed both KIF3B and CLC-5, 42 vesicles expressed KIF3B only, and 28 vesicles expressed CLC-5 only. Thus, of the 110 vesicles expressing KIF3B, 62\% showed colocalization with CLC-5, and of the 96 vesicles expressing CLC-5, 71\% showed colocalization with KIF3B. A mean $( \pm$ SE) of 14
$( \pm 1.6)$ of the $28( \pm 1.7)$ vesicles within a cell demonstrated colocalization of CLC-5 with KIF3B, and the total cell area occupied by each of KIF3B- and CLC-5-containing vesicles within these cells was $3.4 \%$. The observed frequency of CLC-5 and KIF3B colocalization was significantly higher at $2.3 \%(P<0.001)$ than that expected to occur at random, which is estimated to be $0.12 \%$ (i.e., $3.4 \%$ of $3.4 \%$ ), thereby indicating that the observed colocalization of CLC-5 and KIF3B is $\sim 20$-fold greater than that expected to occur by chance alone. CLC-5 was also demonstrated to be associated with microtubules by costaining with anti- $\alpha$-tubulin (Fig. $2 B$ ) and to colocalize with the Kinesin- 2 complex that 

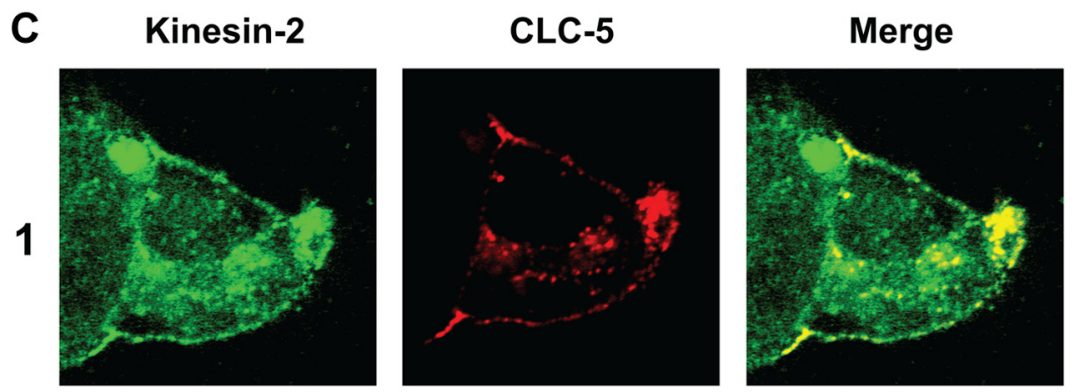

D
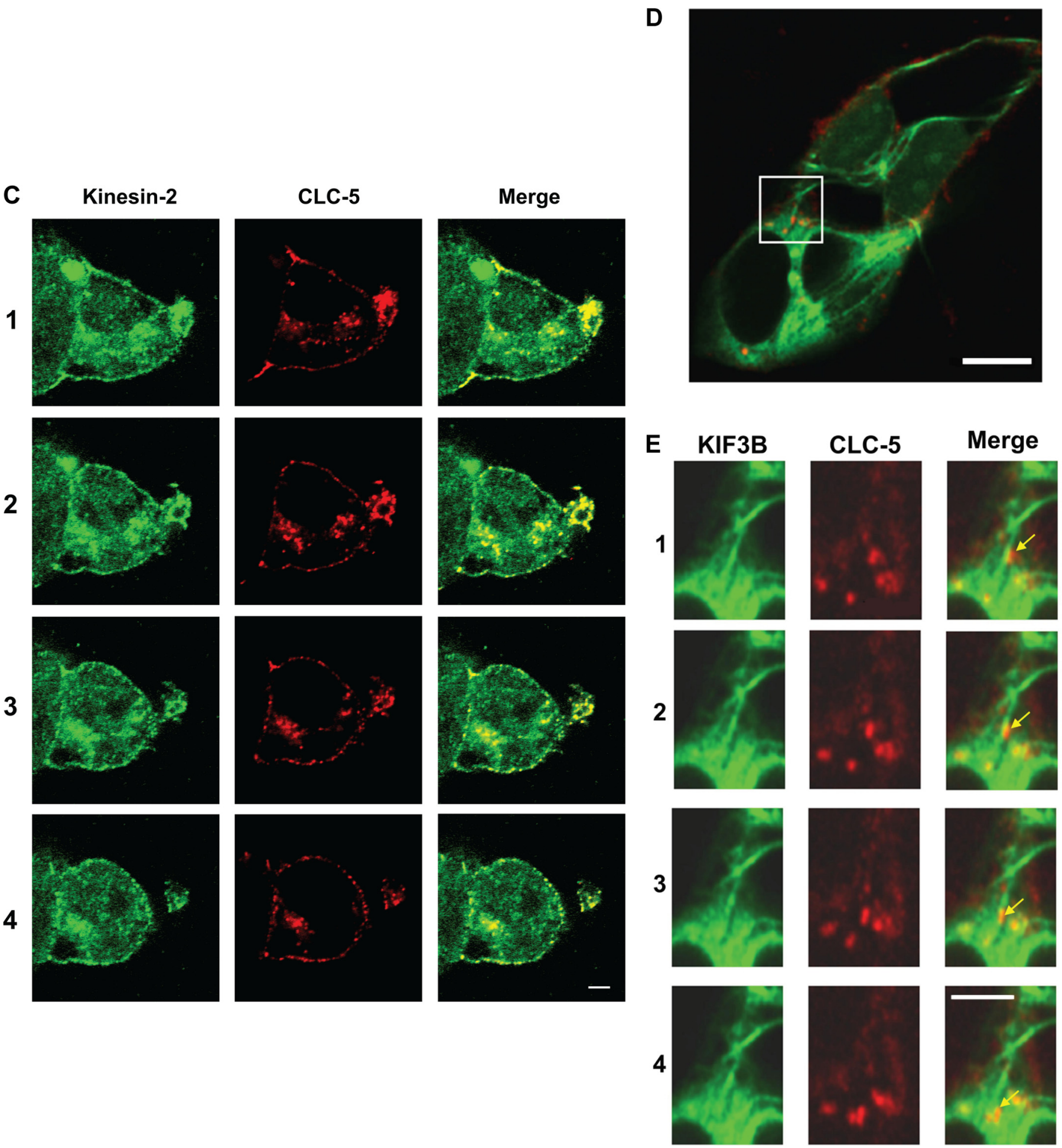

Fig. 2-Continued

contains KIF3B (Fig. 2C). In addition, the microtubular location of CLC-5-containing vesicles and KIF3B was further demonstrated by the use of nocodazole, which inhibits polymerization of free tubulin molecules (14). The extent of microtubule depolymerization after nocodazole treatment, and restoration following nocodazole wash-out, was verified by anti- $\alpha$-tubulin staining. Nocodazole treatment of trans- fected HEK293 cells resulted in a disruption of microtubule integrity and a dramatic redistribution of CLC-5 and KIF3B (data not shown).

Live cell imaging using cotransfected HEK293 and COS7 (data not shown) cells demonstrated that CLC-5-containing vesicles were transported along the KIF3B-labeled cytoskeletal network structures (Fig. 2, D and $E$ ). These vesicles 
were estimated to move at an approximate rate of $0.42 \mu \mathrm{m} / \mathrm{s}$. Thus, KIF3B and CLC-5 colocalize within the cell, thereby supporting the yeast two-hybrid and coimmunoprecipitation data (Fig. 1, $B-F$ ), which indicate that the two proteins physically interact.

Effects of CLC-5 and KIF3B interaction on chloride currents, cell surface CLC-5 expression, and CLC-5 internalization in nonpolarized HEK293 cells. The functional significance of the CLC-5 and KIF3B interaction was investigated further by electrophysiological studies in HEK293 cells, which are a nonpolarized but well-established mammalian cell system for recording CLC-5 currents (12). Large, outwardly rectifying whole cell currents were recorded from HEK293 cells transfected with CLC-5 (Fig. 3A) or cotransfected with KIF3B (Fig. $3 B$ ), but not from untransfected cells (Fig. $3 C$ ). These currents were strongly voltage dependent and activated at potentials above $+30 \mathrm{mV}$. The presence of KIF3B resulted in a $45 \%$ increase in the amplitude of CLC-5 currents. The maximum conductance $\left(G_{\max }\right)$, which is a measure of antiporter density, was significantly increased in cells coexpressing CLC-5 and KIF3B (FL)-HA (30.4 $\pm 3.2 \mathrm{nS}, n=10)$, compared with cells expressing CLC-5 and pCMV-HA alone $(20.9 \pm 1.5 \mathrm{nS}, n=$ $5 ; P<0.02$; Fig. $3 D$ ). This increase in membrane conductance occurred without any effect on voltage-dependent gating. These data demonstrated a specific and functional interaction between CLC-5 and KIF3B and indicate a role for KIF3B in regulating CLC-5 currents.

KIF3B forms a heterotrimeric complex with KIF3A and KAP3, and the functional effects of KIF3B deletional constructs consisting of KIF3B MD/CC or KIF3B CC/GD and a hydrolysis-deficient mutant (KIF3B-ATP) were assessed. These constructs were particularly selected as they have been reported to exert dominant-negative effects in dividing cells (18). Coexpression of CLC-5 with the KIF3B MD/CC, CC/ GD, or -ATP constructs did not increase $G_{\max }(n=10$ each), when compared with CLC-5 and pCMV-HA alone $(n=10)$. These results are in keeping with a dominant-negative effect in which the mutant KIF3B proteins compete with the endogenous normal KIF3B proteins for dimerization with the KIF3A subunit. However, this requires cautious interpretation as the effects of such dominant-negative constructs increase gradually with time, as they require incorporation into new Kinesin-2 heterotrimers before they can interfere with motility (2). Thus, our results (Fig. 3D), which were observed at $48 \mathrm{~h}$ posttransfection, may be consistent with this slow time course.

The increase in the amplitude and $G_{\max }$ of CLC-5 currents (Fig. 3D) observed when KIF3B was coexpressed could be explained by an increased number of CLC- 5 antiporters at the cell surface. We investigated this possibility by using cell surface biotinylation to determine any changes in surface levels of CLC-5 in response to coexpression with KIF3B and its deletional constructs (Fig. 3E). Each experimental protocol was repeated five times on separate batches of cells. Coexpression of CLC-5 with KIF3B (FL)-HA in HEK293 cells caused a significant increase in CLC-5 cell surface expression compared with control HEK293 cells cotransfected with CLC-5 and pCMV-HA alone $(n=5 ; P<0.02$; Fig. $3 E)$. Coexpression of CLC-5 with the KIF3B MD/CC, CC/GD, or -ATP constructs revealed no significant effect on CLC-5 cell surface expression when compared with CLC-5 and pCMV-HA alone (Fig. 3E). These results demonstrate that the KIF3B-mediated changes in CLC- 5 currents were due to changes in cell surface levels of the antiporter.

The increase in the cell surface levels of CLC-5 in response to KIF3B overexpression in HEK293 cells could result either from an increased delivery of CLC-5 to the surface or from a decrease in CLC-5 internalization. However, in nonpolarized cells, such as HEK293 cells, the microtubules are organized with the positive ends toward the cell surface (Fig. $3 F$ ), and hence KIF3B will be transporting its cargo anterogradely toward the cell surface. Thus, overexpression of KIF3B in HEK293 cells is predicted to increase the transport of CLC-5 toward the cell surface, and this is consistent with the observed significant increase in CLC-5 currents and cell surface expression (Fig. 3, $D$ and $E$ ). We further investigated the specificity of the role of KIF3B in regulating CLC-5 currents and plasma membrane levels by the use of siRNA. KIF3B was downregulated with siRNA causing a reduction in protein levels to $51 \pm$ $1.9 \%$ compared with control, i.e., nonsense siRNA $(n=4 ; P<$ 0.03 ), whereas those of KIF3A and tubulin remained unchanged (Fig. 3, $G$ and $H$ ). Whole cell currents were measured from HEK293 cells expressing CLC-5 alone or coexpressing CLC-5 and KIF3B siRNA or control siRNA. The coexpression of KIF3B siRNA significantly reduced $G_{\max }$ from $22.8 \pm 2.2$ $\mathrm{nS}(n=10)$ to $12.3 \pm 0.9 \mathrm{nS}(n=9 ; P<0.001$; Fig. $3 I)$. Coexpressing control siRNA had no significant effect on $G_{\max }$ $(22.9 \pm 8 \mathrm{nS}, n=10)$. To investigate whether this decrease in conductance is due to decreased expression of antiporters at the cell surface, we coexpressed CLC-5 with KIF3B siRNA and found that there was a significant decrease in CLC-5 cell surface expression compared with HEK293 cells cotransfected with CLC-5 and control siRNA $(n=6 ; P<0.01$; Fig. $3 J)$. These results further demonstrate the functional interaction between CLC-5 and KIF3B in regulating chloride currents and CLC-5 cell surface expression.

Effects of CLC-5 and KIF3B interaction on albumin transferrin and endocytosis in nonpolarized HEK293 and polarized OK cells. The data from the electrophysiological and biotinylation studies showed that chloride currents (Fig. 3, D and $I$ ) and the cell surface levels of CLC-5 (Fig. 3, $E$ and $J$ ) could be regulated by KIF3B in HEK293 cells. Cell surface levels of CLC-5 are rate limiting for albumin uptake (25), and to further assess the functional interaction between CLC-5 and KIF3B, we initially investigated its effects on albumin uptake in HEK293 cells. HEK293 cells, which have previously been shown to express endogenous CLC-5 (7), were shown to have endogenous expression of megalin and KIF3B, but not cubilin (Fig. $3 K$ ). Thus, they could be used to study albumin uptake via the megalin-dependent receptor-mediated pathway (4) but not transferrin uptake, which specifically requires binding to cubilin for its renal tubular reabsorption (34). HEK293 cells were transfected with KIF3B (FL), pCMV-HA, KIF3B siRNA, or control siRNA constructs. Coexpression of KIF3B (FL) significantly increased albumin uptake to $107 \pm 2 \%(n=4 ; P<$ 0.02) of control levels (Fig. $3 L$ ). The MD/CC, CC/GD, and -ATP constructs had no significant effect (data not shown). Moreover, in cells in which KIF3B was downregulated, albumin uptake was significantly reduced to $60 \pm 5 \%$ of control levels $(n=6 ; P<0.02$; Fig. $3 L)$. In addition, in HEK293 cells transfected with KIF3B (FL), pCMV-HA, KIF3B siRNA, or control siRNA constructs, the uptake of fluorescently labeled albumin was significantly decreased $(n=6 ; P<0.001)$ by 

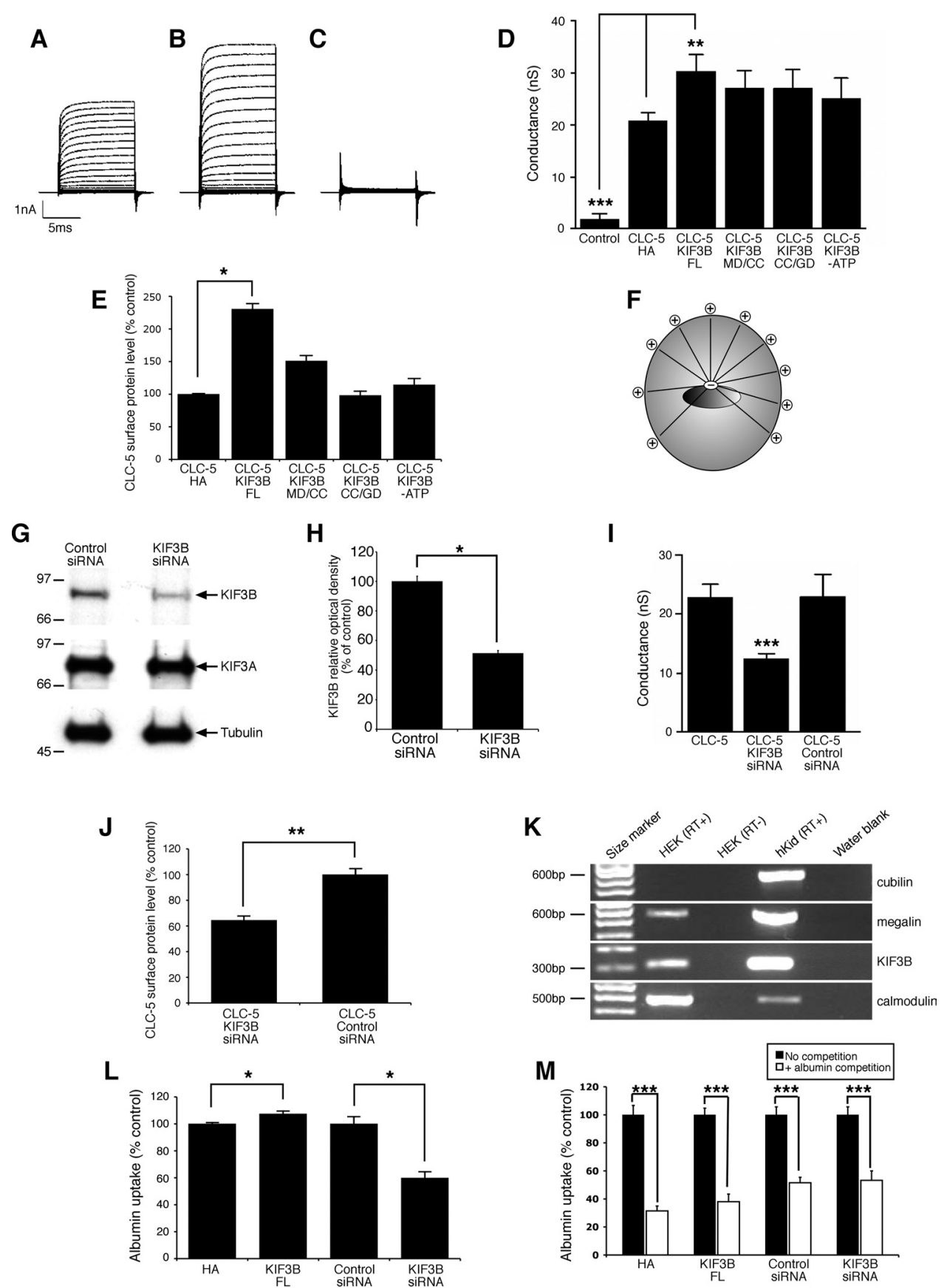

Fig. 3. Electrophysiological, cell surface expression, and albumin uptake studies in nonpolarized HEK293 cells. $A$ - $C$ : representative current recording from a HEK293 cell expressing CLC-5 (A), CLC-5 and KIF3B (B), and an untransfected HEK293 cell (C). D: maximum conductance measured from HEK293 cells cotransfected with CLC-5 and expression plasmids as indicated. Coexpression of KIF3B (FL) significantly increased conductance. E: densitometric analysis of CLC-5 in cell surface fractions. Coexpression of KIF3B (FL) significantly increased the cell surface expression of CLC-5. F: microtubule orientation in nonpolarized HEK293 cells. G: representative Western blot analysis for KIF3B, KIF3A, and tubulin expression in cell lysates obtained from HEK293 cells transfected with control or KIF3B siRNA. KIF3B siRNA suppressed endogenous KIF3B expression, whereas there was no effect on KIF3A and tubulin expression. $H$ : densitometric analysis of KIF3B expression in cell lysates obtained from HEK293 cells transfected with control or KIF3B siRNA. KIF3B siRNA significantly reduced expression of endogenous KIF3B. I: maximum conductance measured from HEK293 cells cotransfected with CLC-5 and KIF3B siRNA or control siRNA plasmids as indicated. KIF3B siRNA significantly decreased conductance compared with coexpression of CLC-5 with control siRNA. $J$ : densitometric analysis of CLC-5 in cell surface fractions. KIF3B siRNA significantly decreased the cell surface expression of CLC-5, compared with coexpression of CLC-5 with control siRNA $(n=6)$. K: RT-PCR analysis of cubilin, megalin, KIF3B, calmodulin (positive control), and water blank (negative control) in HEK293 cells and control human kidney (hKid). L: albumin uptake in HEK293 cells transfected with KIF3B constructs. KIF3B (FL) significantly increased albumin uptake, whereas KIF3B siRNA significantly decreased albumin uptake, compared with their respective controls. $M$ : competition assays for albumin uptake. HEK293 cells were transfected with KIF3B constructs, in the absence (no competition) or presence (albumin competition) of excess unlabeled albumin, and the uptake of fluorescently labeled albumin measured $(n=6)$; the uptake of fluorescently labeled albumin without competition was taken as the reference and set at $100 \%$ and compared with that obtained with competition using unlabeled albumin. Endocytosis of the fluorescently labeled albumin was significantly reduced by competition with unlabeled albumin. Means $\pm 1 \mathrm{SE}$ and $P$ values calculated by Student's unpaired, 2-tailed $t$-test are shown. $* P<0.02$, $* * P<0.01$, and $* * * P<0.001$. 
incubation in the presence of excess unlabeled albumin (Fig. $3 M$ ), indicating that the albumin uptake involves a receptormediated pathway. Thus, these results are in agreement with those of the electrophysiology and biotinylation studies and further demonstrate the functional interaction between CLC-5 and KIF3B. These results clearly show that KIF3B is a specific physiological regulator of constitutive receptor-mediated albumin uptake in HEK293 cells.

However, HEK293 cells are nonpolarized cells and have their microtubules organized with the positive ends toward the cell surface (Fig. $3 F$ ), whereas in polarized renal epithelial cells the microtubules are organized with their minus ends toward the apical surface and their plus ends extending through the cell body to the basolateral surface (Fig. 4A). Moreover, HEK293 cells do not express cubilin (Fig. $3 K$ ) and hence cannot be used to study endocytosis of other molecules such as transferrin. We therefore investigated the effects of KIF3Baltered expression on the cell surface expression and internalization of CLC-5 and their consequences for albumin and transferrin uptake in polarized monolayers of OK cells. OK cells are a representative model for renal proximal tubular cells and have been reported to express megalin, cubilin, and CLC-5

\section{A}

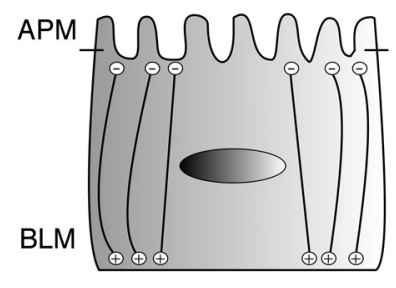

B

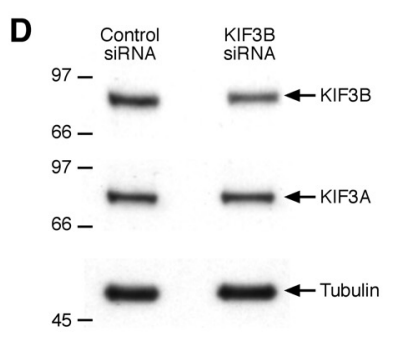

$\mathbf{F}$

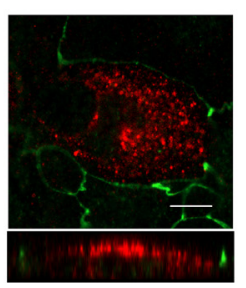

H

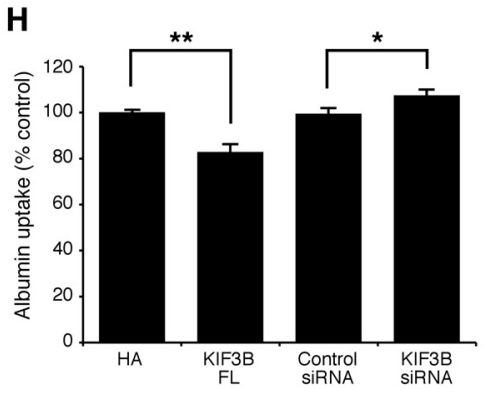

J

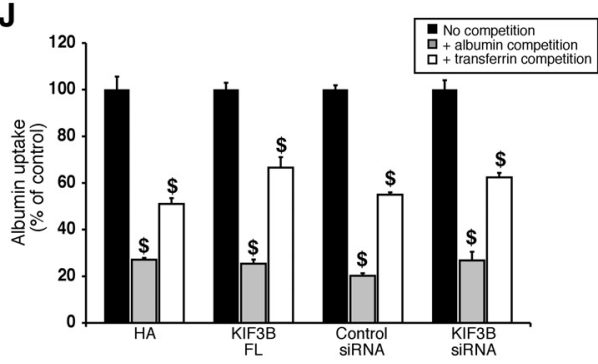

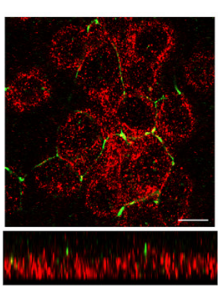

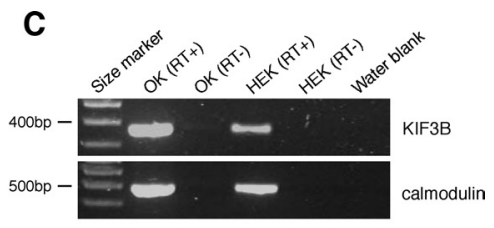

E

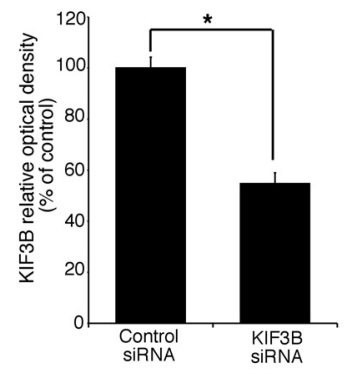

G

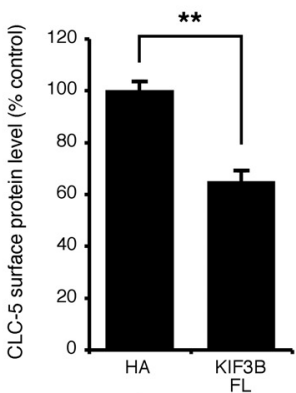

I

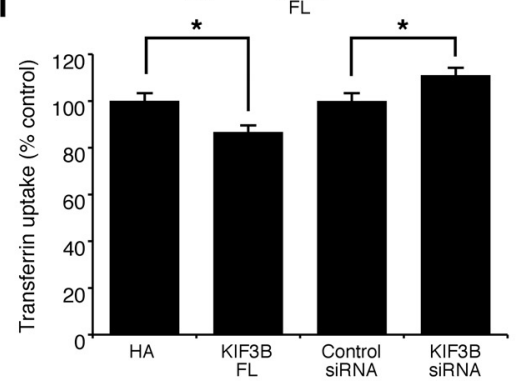

K

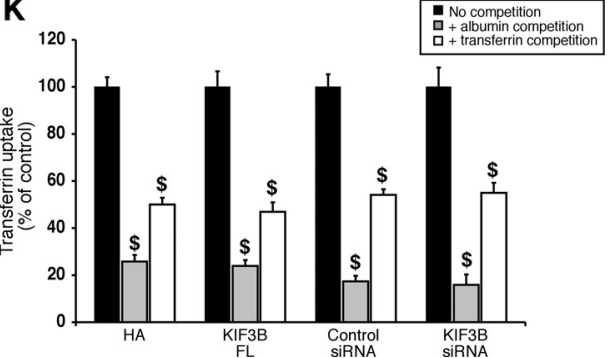


$(7,62)$, which facilitate receptor-mediated endocytosis of albumin and transferrin (54). Albumin is a ligand for both megalin and cubilin, whereas transferrin is a ligand for cubilin only (54). To investigate further the role of the CLC-5 and KIF3B interaction in polarized renal epithelial cells, we first established that the OK cells were polarized in culture (Fig. $4 B$ ) and that they also expressed KIF3B (Fig. 4C). OK cells were shown to be polarized in culture by demonstrating the presence of ZO-1-immunostained tight junctions and the presence of microtubules that were orientated with their plus ends extending through the cell body to the basolateral surface, as demonstrated by basolateral expression of EB1 (Fig. 4B). OK cells were also shown to endogenously express KIF3B (Fig. $4 C$ ), which could be significantly downregulated with KIF3B siRNA, causing a reduction in protein levels to $55 \pm 4.3 \%$, compared with control ( $n=4 ; P<0.05$; Fig. 4, $D$ and $E$ ). Finally, we demonstrated that Myc-tagged CLC-5 expression in these polarized OK cells occurred at the apical cell surface (Fig. 4F) and that the Myc epitope was not associated with aberrant sorting of the Myc-tagged CLC-5 to the basolateral membrane. The orientation of the microtubules (Fig. 4, $A$ and $B$ ) would predict that overexpression of KIF3B would result in a decrease in the apical cell surface expression of CLC-5 and an increase in CLC-5 endocytosis. Indeed, this is the case as coexpression of CLC-5 with KIF3B (FL)-HA in OK cells caused a significant decrease in CLC-5 cell surface expression compared with control OK cells transfected with CLC-5 and pCMV-HA alone $(n=9 ; P<0.02$; Fig. $4 G)$. These results indicate that when KIF3B is overexpressed in polarized $(\mathrm{OK})$ cells, anterograde transport of CLC-5-containing vesicles away from the cell surface is increased, thereby reducing the number of CLC-5 antiporters at the cell surface. This would be predicted to reduce albumin and transferrin uptake by the receptor-mediated pathway that involves the megalin-cubilin receptor complex (54), and we tested this hypothesis by transfecting OK cells with KIF3B (FL)-HA, or pCMV-HA alone constructs. In addition, we investigated the effects of KIF3B downregulation in OK cells, by use of KIF3B siRNA or control
siRNA constructs. Overexpression of KIF3B (FL) significantly reduced albumin uptake to $83 \pm 4 \%$ of control levels $(n=6$; $P<0.02$ ), whereas downregulation of KIF3B significantly increased albumin uptake to $107 \pm 2 \%(n=12 ; P<0.05$; Fig. $4 H$ ). Overexpression of KIF3B (FL) also significantly reduced transferrin uptake to $87 \pm 3 \%(n=6 ; P<0.05)$ of control levels, whereas downregulation of KIF3B significantly increased transferrin uptake to $111 \pm 3 \%$ of control levels $(n=$ $12 ; P<0.05$; Fig. 4I). In addition, in OK cells transfected with KIF3B (FL), pCMV-HA, KIF3B siRNA, or control siRNA constructs, the uptake of fluorescently labeled albumin was significantly decreased by incubation in the presence of excess unlabeled albumin or unlabeled transferrin $(n=6 ; P<0.001$; Fig. 4J). Similarly, the uptake of fluorescently labeled transferrin was significantly decreased by incubation in the presence of excess unlabeled albumin or unlabeled transferrin $(n=6$; $P<0.001$; Fig. $4 K)$. These combined data demonstrate that excess of albumin will block the available binding sites on the megalin-cubilin receptor complex and therefore decrease the endocytosis of fluorescently labeled albumin and transferrin; similarly, an excess of transferrin will block the available binding site on cubilin and therefore decrease endocytosis of fluorescently labeled albumin and transferrin. Thus, these results demonstrate that KIF3B is a specific physiological regulator of constitutive albumin and transferrin uptake in polarized OK cells via a receptor-mediated pathway that involves the megalin-cubilin receptor complex.

Clc-5 and Kif3b interaction studies in $\mathrm{Clcn}^{\mathrm{Y/+}}$ and Clcn5 ${ }^{Y /-}$ mouse kidneys. The cellular studies (Figs. 1-4) establish that CLC-5 and KIF3B interact and that this interaction is important for the cell surface expression of CLC-5, CLC-5 currents, and in facilitating endocytosis of albumin and transferrin. To demonstrate further the CLC-5 and KIF3B interaction and its role in endocytosis, we undertook studies using kidneys from normal male mice $\left(\mathrm{Clcn} 5^{\mathrm{Y} /+}\right)$ and mutant male mice deleted for $\mathrm{Clcn} 5\left(\mathrm{Clcn5} 5^{\mathrm{Y} /-}\right)$. A lack of Clc-5 in Clcn $5^{\mathrm{Y} /-}$ kidneys resulted in significantly increased Kif $3 \mathrm{~b}$ mRNA and protein expression, as assessed by qPCR (Fig. 5A)

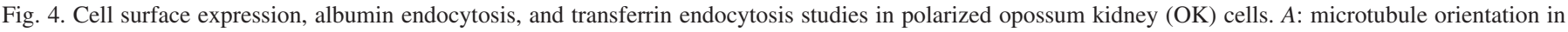

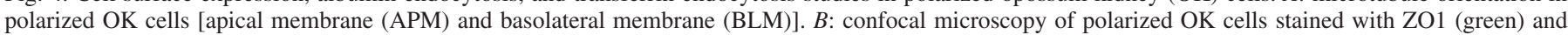

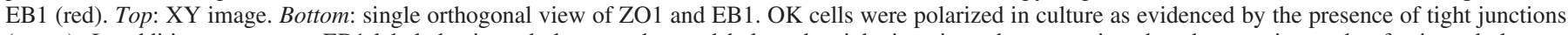

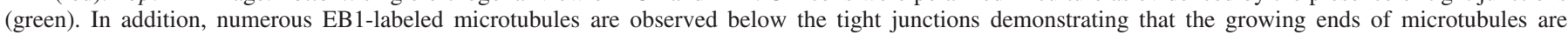

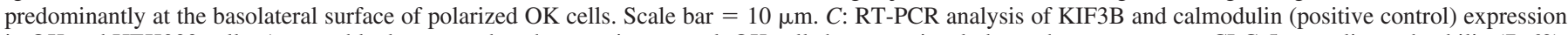

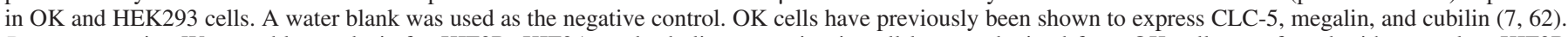

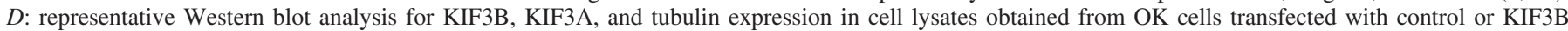

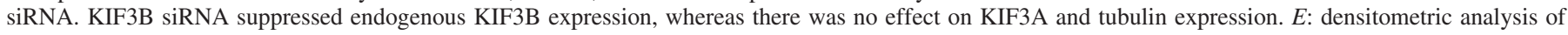

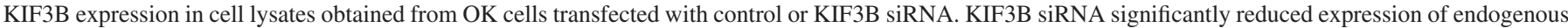

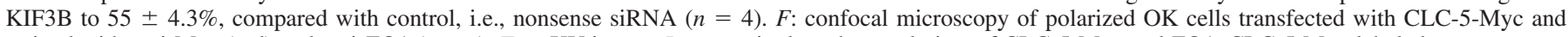

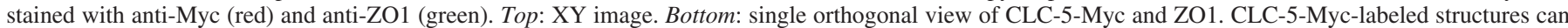

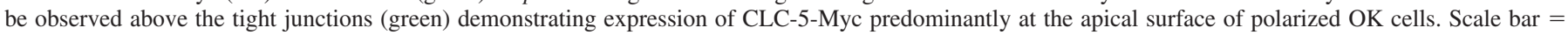

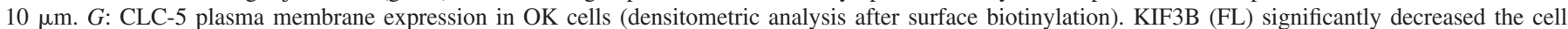

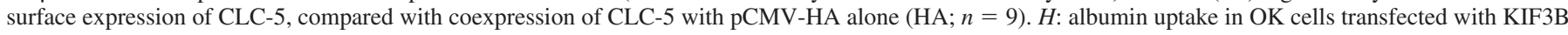

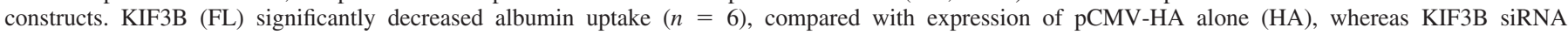

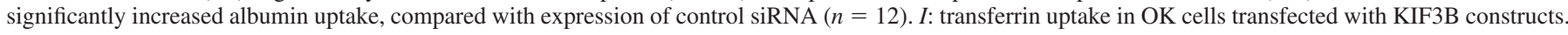

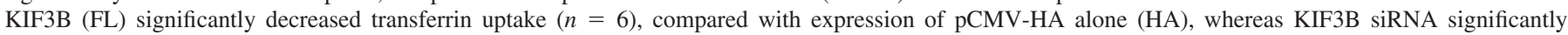

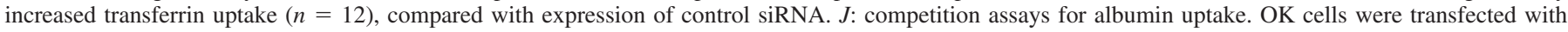

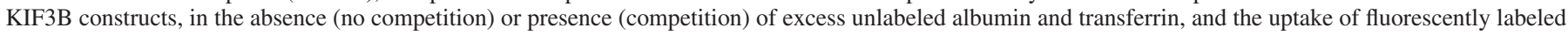

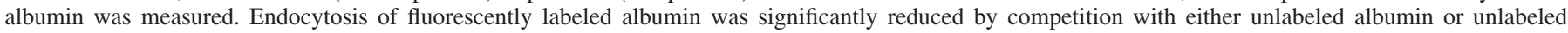

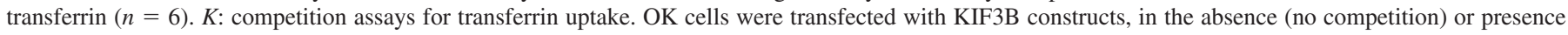

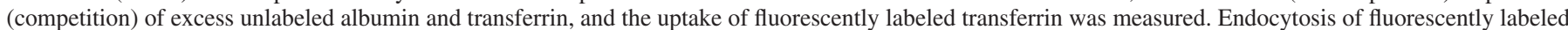

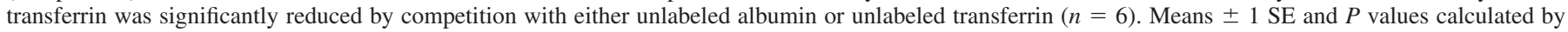
Student's unpaired, 2-tailed $t$-test are shown; ${ }^{*} P<0.05, * * P<0.02, \$ P<0.001$.
} 

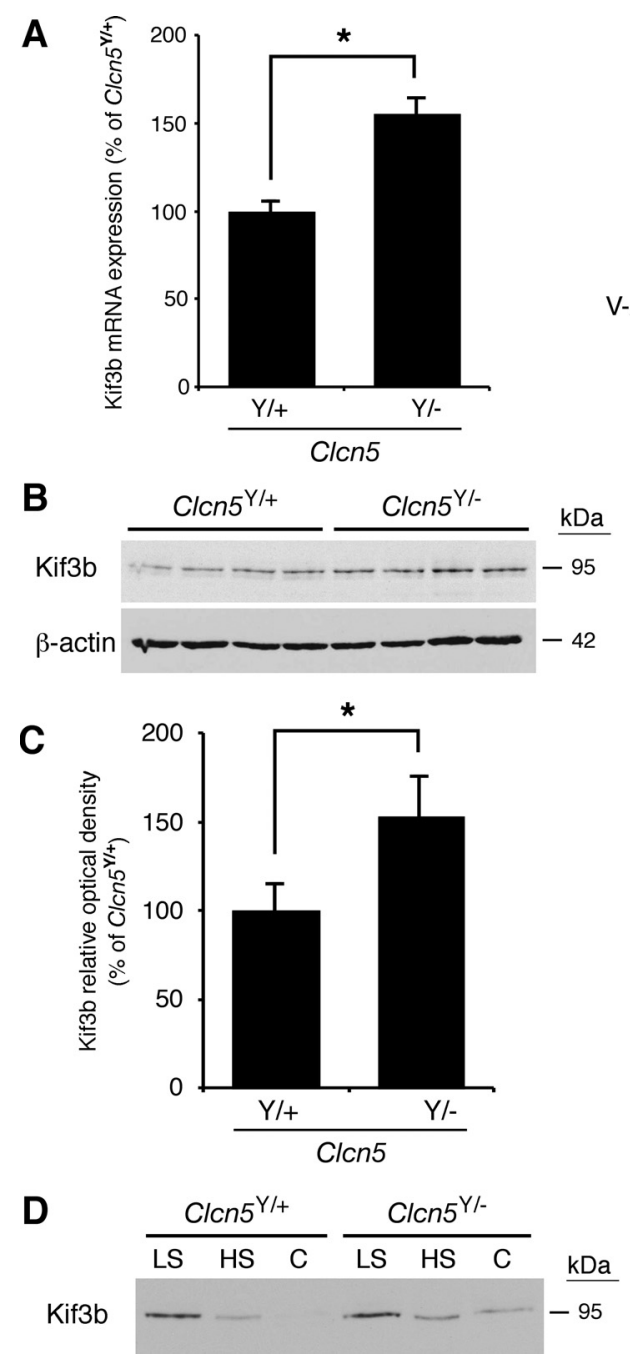

E Fraction number
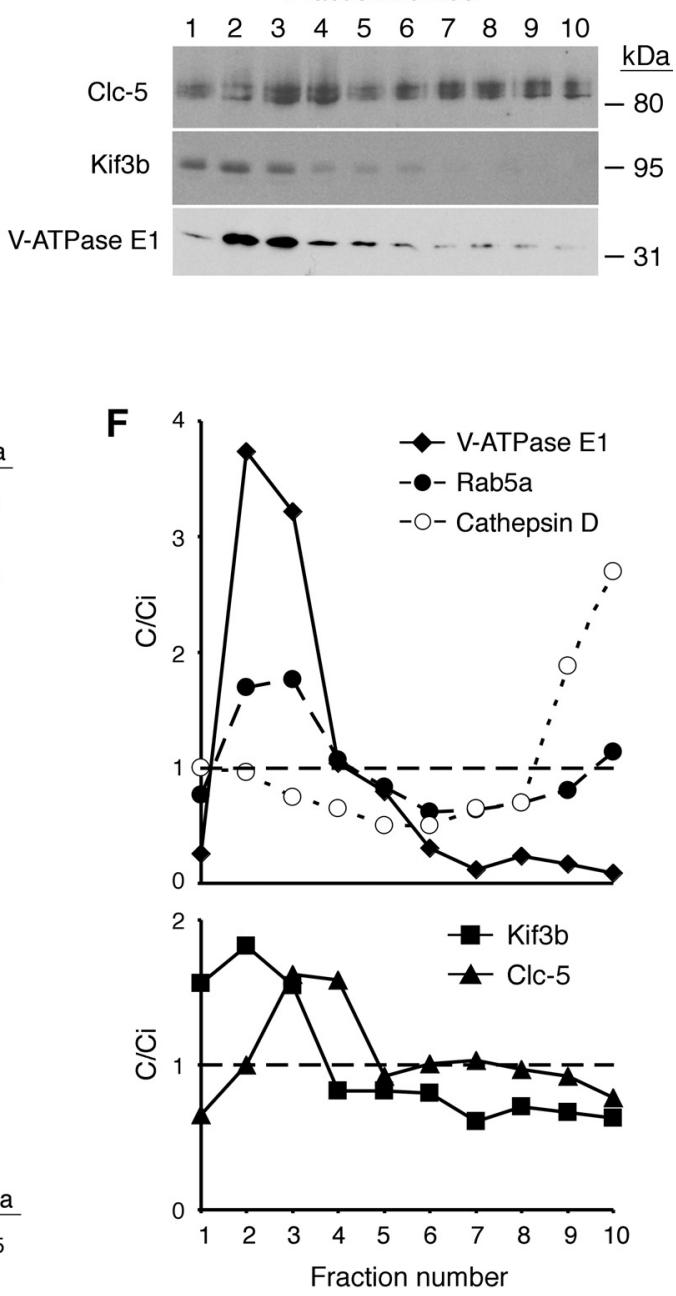

and Western blot analysis (Fig. 5, $B$ and $C$ ). Investigations of subcellular fractionations of kidneys from $\mathrm{Clcn} 5^{\mathrm{Y} /+}$ and $\mathrm{Clcn} 5^{\mathrm{Y} /-}$ mice revealed that Kif3b was abundantly present in the low-speed pellet and to a lesser extent also in the highspeed pellet (Fig. 5D). Interestingly, whereas the high-speed supernatant (cytosol) of wild-type mice kidneys showed no detectable signal for Kif3b, this band was detected in $\mathrm{Clcn} 5^{\mathrm{Y} /-}$ mouse kidneys, indicating a defect of recruitment with sedimentable material. This altered subcellular distribution of Kif3b in $C l c n 5^{\mathrm{Y} /-}$ mice, which was confirmed by densitometry (data not shown), may be a reflection of the increased expression of Kif3b associated with a loss of Clc-5. Further analysis of the high-speed pellet by isopycnic centrifugation revealed that Kif3b equilibrated at low density, partly overlapping with the endosomal markers Rab5a and the V-ATPase E1 subunit and partially with Clc-5, but was fully resolved from the lysosomal marker cathepsin D (Fig. 5, $E$ and $F$ ). Thus, these data support a significant association of Kif3b with Clc-5 and endosomes.

To study further the role of the CLC-5 and KIF3B interaction in albumin endocytosis, primary cell cultures of mPTCs, which are polarized and differentiated (13), were prepared from the kidneys of $C l c n 5^{\mathrm{Y} /+}$ and $C l c n 5^{\mathrm{Y} /-}$ mice, as described previously (51). qPCR analysis using RNA from these mPTCs revealed that endogenous Kif $3 b$ expression was significantly higher in the mPTCs of $\mathrm{Clcn}^{\mathrm{Y} /-}$ mice (Fig. 6A). This finding is consistent with the observations of increased Kif3b expression in whole kidney extracts from $\mathrm{Clcn} 5^{\mathrm{Y} /-}$ mice (Fig. 5, $A-D)$. Fluorescently labeled albumin endocytosis in the absence or presence of excess unlabeled albumin or transferrin was investigated in $\mathrm{Clcn}^{\mathrm{Y} /+}$ and $\mathrm{Clcn} 5^{\mathrm{Y} /-}$ mPTCs that were either untransfected or transfected with human GFP-tagged KIF3B (Figs. 6, $B$ and $C$ ). The transfection efficiency of human $\mathrm{KIF3B}$ (hKIF3B) in mPTCs, as assessed by GFP expression, was $\sim 40 \%$ in mPTC cultures from both $C l c n 5^{\mathrm{Y} /+}$ and $C l c n 5^{\mathrm{Y} /-}$ mice (data not shown), and $h K I F 3 B$ expression, as assessed by qPCR, in the transfected mPTCs was $\sim 3,000$-fold higher than the endogenous mouse Kif3b and Kif3a (Fig. 6B). Studies of albumin uptake, in these polarized cells, revealed a strong decrease in mPTCs of $\mathrm{Clcn} 5^{\mathrm{Y} /-}$ mice compared with mPTCs of $C l c n 5^{\mathrm{Y} /+}$ mice (Fig. 6C). The residual uptake of FITC-BSA in $\mathrm{Clcn}^{\mathrm{Y} /-}$ cells may indicate that Clc-5 strongly promotes but is not absolutely essential for receptor-mediated endocytosis. Alternatively, these observations may reflect a Clc-5-independent endocytic pathway, such as caveolin-dependent endocytosis. Indeed, caveolin-1 and caveolin-2 were shown to be expressed in HEK293 and OK cells, mouse kidney, and mPTCs (Fig. 6D), and expression of caveolin-2 
A

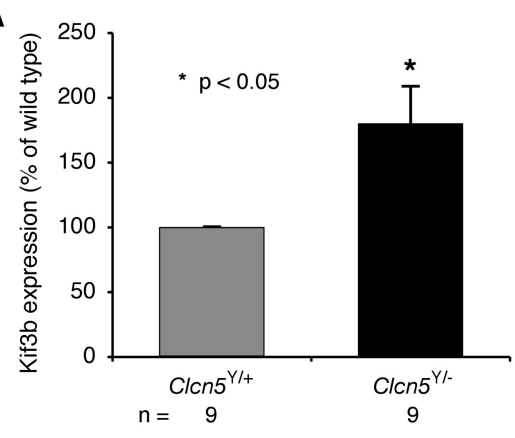

C

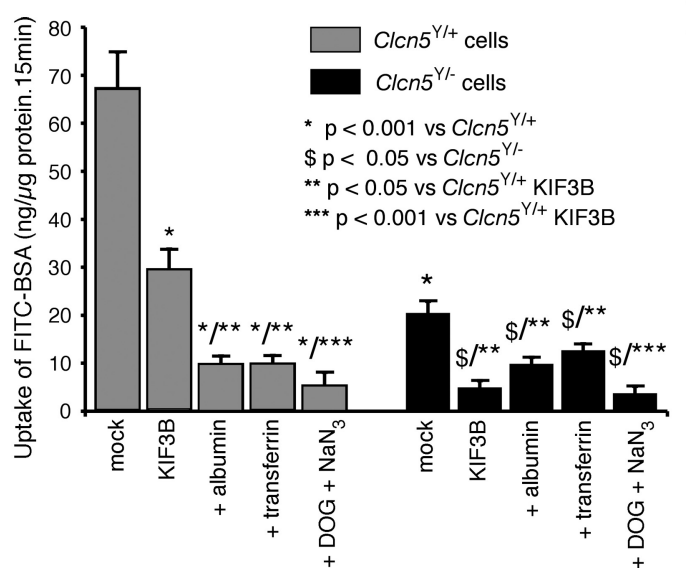

B

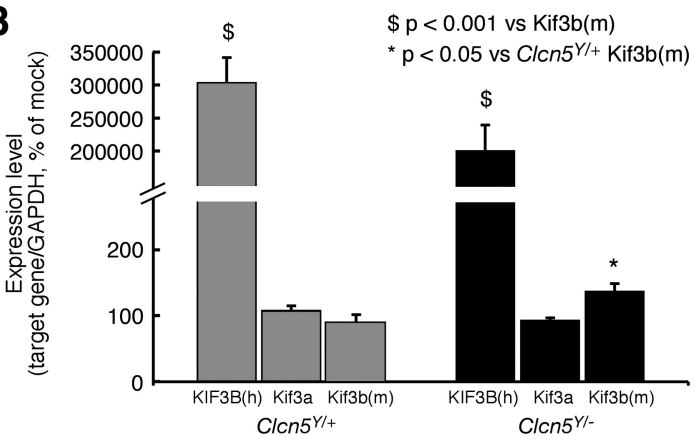

$\mathbf{D}$

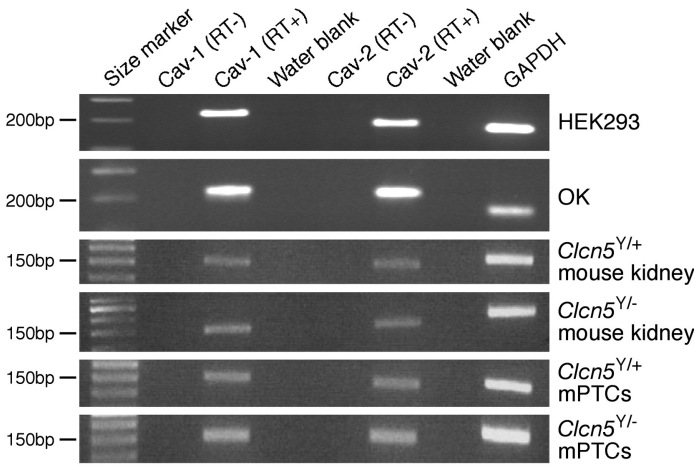

Fig. 6. Endogenous Kif3b expression and albumin endocytosis in mouse proximal renal tubular primary cell cultures (mPTCs). A: endogenous expression of Kif3b in mPTC cultures from $C l c n 5^{\mathrm{Y} /+}$ and $C l c n 5^{\mathrm{Y} /-}$ mice. The expression of Kif $3 b$ was determined by qPCR and was found to be significantly higher in the $C l c n 5^{\mathrm{Y} /-}$ mice and consistent with the observations from mouse whole kidney extracts (Fig. 5A). B: expression of human KIF3B (hKIF3B) in transfected mPTCs from $C l c n 5^{\mathrm{Y} /+}(n=3)$ and $C l c n 5^{\mathrm{Y} /-}(n=3)$ mice was assessed by qPCR and this showed an $\sim 3,000$-fold higher expression of the exogenous human KIF3B, compared with the endogenous expression of $K i f 3 b[\mathrm{Kif} 3 \mathrm{~b}(\mathrm{~m})]$ and $K i f 3 a$. C: uptake of FITC-albumin in mPTC cultures from $C l c n 5^{\mathrm{Y} /+}$ and $C l c n 5^{\mathrm{Y} /-}$ mice in mock-transfected cells, in the absence or presence of competition by excess unlabeled albumin and transferrin, or after energy depletion by deoxyglucose (DOG) and sodium azide $\left(\mathrm{NaN}_{3}\right)$, or in KIF3B-transfected cells. In Clcn $5^{\mathrm{Y} /+}$ mPTCs, overexpression of hKIF3B decreases specific albumin endocytic uptake. In Clcn $5^{\mathrm{Y} /-} \mathrm{mPTCs}$, albumin uptake is fully abrogated (to the level of metabolic inhibition and albumin competition) by hKIF3B overexpression. D: RT-PCR analyses of caveolin-1 (Cav-1) and caveolin-2 (Cav-2) in HEK293 cells, OK cells, $C l c n 5^{\mathrm{Y} /+}$ and $C l c n 5^{\mathrm{Y} /-}$ whole mouse kidneys, and $C l c n 5^{\mathrm{Y} /+}$ and $C l c n 5^{\mathrm{Y} /-}$ mPTCs. GAPDH and a water blank were used as positive and negative controls, respectively. Means \pm 1 SE and $P$ values were calculated by the Student's unpaired, 2-tailed $t$-test.

has been reported to be increased in $\mathrm{Clcn} 5^{\mathrm{Y} /-}$ proximal tubules (57). In both $\mathrm{Clcn} 5^{\mathrm{Y} /+}$ and $\mathrm{Clcn} 5^{\mathrm{Y} /-}$ mPTCs, fluorescently labeled albumin endocytosis was reduced by competition with excess unlabeled albumin and transferrin. These findings are similar to those obtained using the polarized OK cells (Figs. 4, $J$ and $K$ ), and consistent with a role of CLC-5 and KIF3B interaction in facilitating endocytosis via the megalin-cubilin receptor complex $(54,57)$. Thus, an excess of albumin will block the available binding sites on megalin and cubilin and an excess of transferrin will block the available binding sites on cubilin, and both will therefore decrease endocytosis of fluorescently labeled albumin. In addition, this endocytosis by the mPTCs of $\mathrm{Clcn} 5^{\mathrm{Y} /+}$ and $\mathrm{Clcn} 5^{\mathrm{Y} /-}$ mice was essentially abrogated by treatment with DOG and sodium azide $\left(\mathrm{NaN}_{3}\right)$, which block the production of ATP from glycolysis and oxidative phosphorylation, respectively, and hence lead to energy depletion in the cells (50). In $\mathrm{Clcn} 5^{\mathrm{Y} /+} \mathrm{mPTCs}$, overexpression of hKIF3B induced a strong decrease in the uptake of FITC-BSA, but not complete abolishment, as evidenced by the residual level of endocytosis that was reduced by competition with albumin and transferrin excess, or metabolic inhibition (Fig.
6C). However, in $C l c n 5^{\mathrm{Y} /-}$ mPTCs, hKIF3B overexpression completely abrogated endocytosis down to the level achieved by energy depletion (Fig. 6C). This further suppression of albumin endocytosis by hKIF3B overexpression in the CLC5-deficient mPTCs indicates that the level of Clc-5 expression influences the effects of KIF3B on albumin endocytosis, and this is consistent with the role of KIF3B in the intracellular trafficking of other membranous organelles (61), such as caveolae, which involves the Kinesin-2 complex (41). Thus, the greater inhibitory effect on FITC-BSA endocytosis observed on hKIF3B overexpression in the absence of Clc-5 indicates that the effects on endocytosis of KIF3B alterations are dependent on Clc-5 expression.

\section{DISCUSSION}

Our results establish an interaction between CLC-5 and KIF3B that is important for the plasma membrane expression of CLC-5, microtubular transport of CLC-5 vesicles, and for albumin uptake in polarized and nonpolarized cells. Thus, in polarized epithelial cells such as OK cells, the interaction 
between CLC-5 and KIF3B results in a reduction in the number of antiporters at the cell surface, as KIF3B is involved in facilitating microtubular transport that removes CLC-5-containing vesicles from the cell surface (Fig. 7). In nonpolarized cells, such as HEK293 cells, the orientation of the microtubules is reversed (Fig. 3F), and the interaction between CLC-5 and KIF3B facilitates transport of CLC-5-containing vesicles to the cell surface. This situation may be analogous to that reported for the interaction between CLC-2 and the microtubule-associated dynein motor complex, which is also involved in regulating CLC-2 cell surface expression through endosomal trafficking (8). However, CLC-2 is ubiquitously expressed, whereas CLC-5 is predominantly expressed in the kidney and extrapolations between these two situations may require cau-

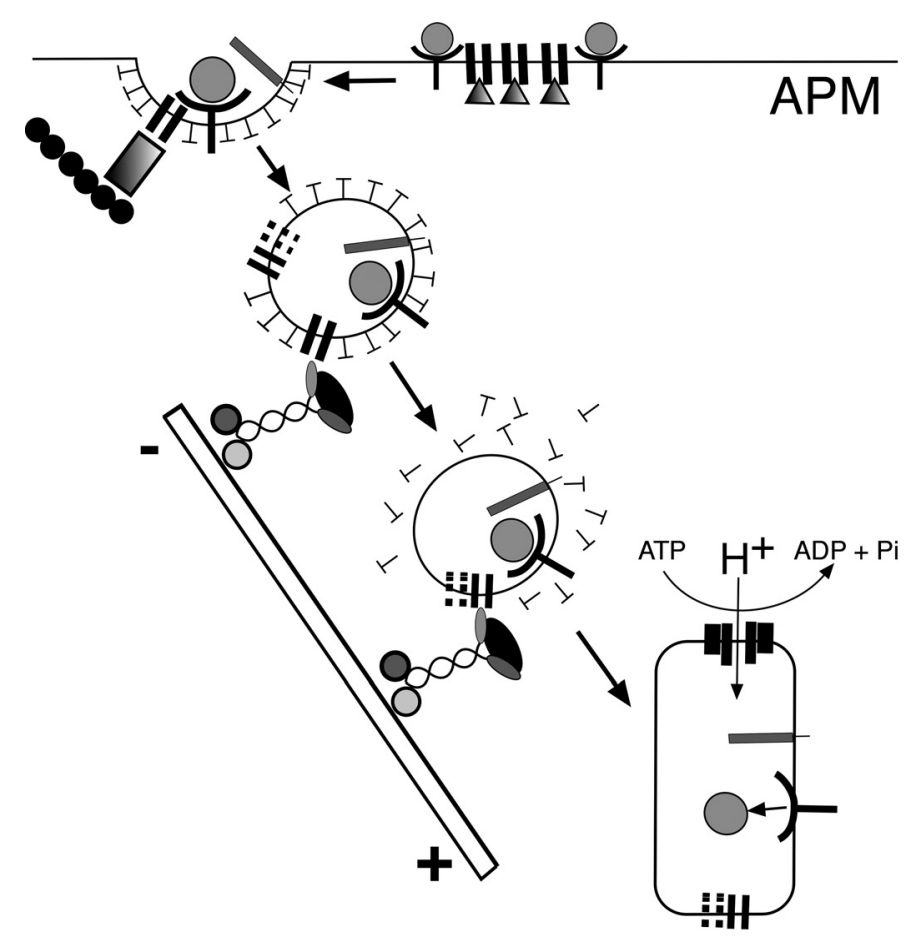

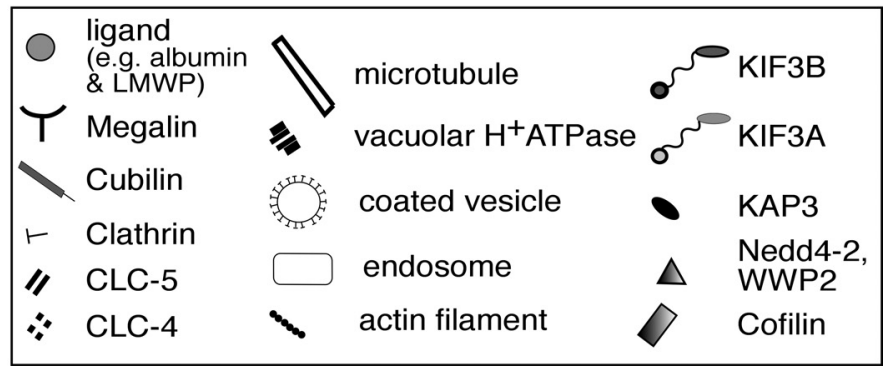

Fig. 7. Schematic representation of a working model for endosomal transport involving CLC-5 and KIF3B interaction in polarized cells. CLC-5 and KIF3B are expressed in polarized renal proximal tubular cells which reabsorb proteins and solutes via the receptor-mediated endocytic pathway that uses megalin and cubilin as the apical plasma membrane (APM) receptors $(4,7,17)$. Ligands bind to these receptors at the APM where CLC-5 and interacting proteins Nedd4-2, NHERF2, and cofilin are also present $(23,24,26)$. The receptorligand complex is internalized in vesicles, containing CLC-5 and CLC-4 (40), which are anterogradely transported along microtubules via the Kinesin-2 complex (17). These vesicles fuse with early endosomes where acidification involves the vacuolar $\mathrm{H}^{+}$-ATPase, with counter ions being provided by CLC-5 (28). In nonpolarized cells, the orientation of the microtubules is reversed (Fig. $3 F$ ), and CLC-5 vesicles would be transported to the cell surface. tious interpretation. In the kidney, CLC-5 plays an obligate role in facilitating albumin uptake by the proximal tubule $(7,47)$, where the cell surface availability of CLC- 5 could be predicted to be a rate-limiting step in albumin uptake. Indeed, the marked reduction of albumin uptake by mPTCs of CLC-5-deficient mice (Fig. 6C) is consistent with an important role for CLC-5 in albumin endocytosis. However, the polarized mPTCs from CLC-5-deficient mice are capable of albumin uptake, although at a reduced level. This residual albumin endocytosis is unlikely to be due to compensation by CLC-4, since previous experiments in CLC-5-deficient mPTCs have shown no further reduction in albumin uptake after removal of $\mathrm{Cl}^{-}$ions and inhibition of endosomal acidification (56). This indicates the presence of an alternate CLC-5-independent albumin uptake pathway in mPTCs, whose activity could be altered by KIF3B expression (Fig. 6C). Such an alternative albumin uptake pathway may involve caveolin-1 and caveolin-2, which facilitate albumin transcytosis $(29,38)$. Moreover, it has been suggested that caveolar transport involves the Kinesin-2 complex (41) and this may provide a possible explanation for the observed reduction in albumin uptake in the MPTCs from the $C l c n 5^{\mathrm{Y} /-}$ mice (Fig. 6C), although it is important to note that caveolae are not present at the apical surface of renal epithelial cells (53). However, movement of caveolin-1, which is expressed at the apical membrane of renal epithelial cells (36), is disrupted and ceases following treatment with nocodazole (41) and this is similar to our findings of CLC-5 vesicle disruption following nocodazole treatment. In this endocytic process, the Kinesin-2 complex, which consists of KIF3A, KIF3B, and KAP3 that are all expressed in renal epithelial cells, works as a motor for anterograde transport along the microtubules toward their plus ends $(17,21,60,61)$. In renal epithelial cells, such as OK cells, the microtubules are organized longitudinally with the plus end pointing toward the basolateral surface (Fig. $4 A)(17,21)$. Thus, vesicles that form part of the megalincubilin receptor-mediated endocytic pathway $(4,7)$ and contain CLC-5, via its interaction with KIF3B, will be transported away from the apical membrane and toward the basolateral membrane (Figs. $4 A$ and 7). In our proposed working model for the role of the CLC-5 and KIF3B interaction in endosomal transport, CLC-5 mutations leading to a loss of the CLC-5 and KIF3B interaction will result in a defective microtubular transport of the endocytic vesicles that contain megalin and cubilin, and this in turn will lead to the resorptive abnormalities of solutes and proteins observed in Dent's disease $(4,47)$.

The importance of the interaction between the CLC-5 $\mathrm{COOH}$ terminus and KIF3B is underscored by the observation that $\sim 60 \%$ of CLC-5 mutations causing Dent's disease are associated with a loss of the CLC-5 COOH terminus (58). Furthermore, this microtubule-dependent vesicle transport is likely to be an important contributor to protein endocytosis in the kidney, as nocodazole has been shown to reduce, by $50 \%$, the apical endocytosis of albumin in OK cells (14). The defective protein endocytosis due to mutations of the antiporter CLC-5, which cause Dent's disease, has been attributed to impaired endosomal acidification secondary to a loss of chloride transport $(4,7,16,47,55)$. However, our results show that the mechanism underlying this defect in endocytosis may also involve the interaction between CLC-5 and KIF3B, which facilitates microtubular transport of endocytic vesicles (Fig. 7). 
The COOH terminus of the family of nine mammalian CLCs (CLC-1 to CLC-7, CLC-Ka, and CLC-Kb) is highly conserved and includes the two CBS domains (11). The CLCs and Kinesin family members are also expressed in multiple tissues $(17,28)$, including the kidney and brain (43). These features indicate that interactions between other CLCs and Kinesin family members may be involved in endosomal trafficking and microtubule-dependent transport in other tissues (43), and the findings of our study may have implications for other renal, neural, retinal, muscular, and skeletal disorders associated with CLC mutations $(22,28,32)$. The likelihood of such interactions between CLCs and Kinesin family members and their role in associated diseases is high as it has been established that other transmembrane channels (e.g., the transient receptor protein polycystin-2 and polycystin-2), transporter proteins (e.g., the cystic fibrosis transmembrane regulator and sodiumphosphate cotransporter type IIa), and exchangers (e.g., the sodium-hydrogen exchanger, NHE3) can form functional interactions with intracellular proteins (e.g., the phosphofurin acidic cluster sorting protein, Kinesin-2, NHERF1/2, merlinezrin-moesin, and myosin VIIb) and that these interactions can have a vital impact on their physiological activity $(9,15,20$, 33, 59).

In summary, our studies show that CLC-5 and KIF3B directly interact in vivo and this interaction involves the $\mathrm{COOH}$ terminus of CLC-5 and the CC and GDs of KIF3B. The interaction with KIF3B alters CLC-5 cell surface expression, whole cell chloride current amplitudes, and is associated with altered albumin endocytosis. The role of the interaction with KIF3B is to facilitate microtubular transport and endocytosis of CLC-5-containing vesicles away from the cell surface of polarized epithelial cells. Thus, our findings, which represent a novel mechanism of ion channel and transporter regulation, have elucidated that an interaction between CLC-5 and KIF3B is important for the plasma membrane expression of CLC-5, and for the microtubular transport of endosomes.

\section{ACKNOWLEDGMENTS}

We are grateful to T. J. Jentsch for helpful discussions and B. Guggino for the gift of the Clcn5-deleted mice.

\section{GRANTS}

This work was supported by the Wellcome Trust (A. A. C. Reed, N. Y. Loh, J. D. Lippiat, C. J. Patridge, J. Galvanovskis, P. Rorsman, F. M. Ashcroft, and R. V. Thakker); the Medical Research Council (M. A. Nesbit, A. A. C. Reed, and R. V. Thakker); the National Kidney Research Fund (S. E. Williams and R. V. Thakker); Nuffield Dominions Trust (F. Wu); Belgian agencies FNRS, FRSM, the Foundation Alphonse et Jean Forton, Concerted Research Actions, Inter-University Attraction Poles (P. Courtoy and O. Devuyst), and the EuReGene, FP6, integrated project of the European Community (A. A. C. Reed, N. Y. Loh, S. Terryn, S. E. Williams, F. Jouret, P. Courtoy, O. Devuyst, and R. V. Thakker).

\section{DISCLOSURES}

No conflicts of interest are declared by the authors.

\section{REFERENCES}

1. Basu SK, Goldstein JL, Anderson RG, Brown MS. Monensin interrupts the recycling of low density lipoprotein receptors in human fibroblasts. Cell 24: 493-502, 1981.

2. Brown CL, Maier KC, Stauber T, Ginkel LM, Wordeman L, Vernos I, Schroer TA. Kinesin-2 is a motor for late endosomes and lysosomes. Traffic 6: 1114-1124, 2005.
3. Campbell RE, Tour O, Palmer AE, Steinbach PA, Baird GS, Zacharias DA, Tsien RY. A monomeric red fluorescent protein. Proc Natl Acad Sci USA 99: 7877-7882, 2002.

4. Christensen EI, Devuyst O, Dom G, Nielsen R, Van der Smissen P, Verroust P, Leruth M, Guggino WB, Courtoy PJ. Loss of chloride channel ClC-5 impairs endocytosis by defective trafficking of megalin and cubilin in kidney proximal tubules. Proc Natl Acad Sci USA 100: 8472 8477, 2003.

5. Cole DG, Chinn SW, Wedaman KP, Hall K, Vuong T, Scholey JM. Novel heterotrimeric kinesin-related protein purified from sea urchin eggs. Nature 366: 268-270, 1993.

6. Cupers P, Veithen A, Hoekstra D, Baudhuin P, Courtoy PJ. Three unrelated perturbations similarly uncouple fluid, bulk-membrane, and receptor endosomal flow in rat fetal fibroblasts. Biochem Biophys Res Commun 236: 661-664, 1997.

7. Devuyst O, Christie PT, Courtoy PJ, Beauwens R, Thakker RV. Intrarenal and subcellular distribution of the human chloride channel, CLC-5, reveals a pathophysiological basis for Dent's disease. Hum Mol Genet 8: 247-257, 1999.

8. Dhani SU, Mohammad-Panah R, Ahmed N, Ackerley C, Ramjeesingh M, Bear CE. Evidence for a functional interaction between the $\mathrm{ClC}-2$ chloride channel and the retrograde motor dynein complex. J Biol Chem 278: 16262-16270, 2003.

9. Donowitz M, Cha B, Zachos NC, Brett CL, Sharma A, Tse CM, Li X. NHERF family and NHE3 regulation. J Physiol 567: 3-11, 2005.

10. Dutzler R, Campbell EB, Cadene M, Chait BT, MacKinnon R. X-ray structure of a $\mathrm{ClC}$ chloride channel at $3.0 \mathrm{~A}$ reveals the molecular basis of anion selectivity. Nature 415: 287-294, 2002.

11. Estevez R, Pusch M, Ferrer-Costa C, Orozco M, Jentsch TJ. Functional and structural conservation of CBS domains from CLC chloride channels. J Physiol 557: 363-378, 2004.

12. Friedrich T, Breiderhoff T, Jentsch TJ. Mutational analysis demonstrates that $\mathrm{ClC}-4$ and $\mathrm{ClC}-5$ directly mediate plasma membrane currents. J Biol Chem 274: 896-902, 1999.

13. Gailly P, Jouret F, Martin D, Debaix H, Parreira KS, Nishita T, Blanchard A, Antignac C, Willnow TE, Courtoy PJ, Scheinman SJ, Christensen EI, Devuyst O. A novel renal carbonic anhydrase type III plays a role in proximal tubule dysfunction. Kidney Int 74: 52-61, 2008.

14. Gekle M, Mildenberger S, Freudinger R, Schwerdt G, Silbernagl S. Albumin endocytosis in OK cells: dependence on actin and microtubules and regulation by protein kinases. Am J Physiol Renal Physiol 272: F668-F677, 1997.

15. Guggino WB. The cystic fibrosis transmembrane regulator forms macromolecular complexes with PDZ domain scaffold proteins. Proc Am Thorac Soc 1: 28-32, 2004.

16. Gunther W, Luchow A, Cluzeaud F, Vandewalle A, Jentsch TJ. ClC-5, the chloride channel mutated in Dent's disease, colocalizes with the proton pump in endocytotically active kidney cells. Proc Natl Acad Sci USA 95: 8075-8080, 1998.

17. Hamm-Alvarez SF, Sheetz MP. Microtubule-dependent vesicle transport: modulation of channel and transporter activity in liver and kidney. Physiol Rev 78: 1109-1129, 1998.

18. Haraguchi K, Hayashi T, Jimbo T, Yamamoto T, Akiyama T. Role of the kinesin-2 family protein, KIF3, during mitosis. J Biol Chem 281: 4094-4099, 2006.

19. Hatae T, Ichimura T, Ishida T, Sakurai T. Apical tubular network in the rat kidney proximal tubule cells studied by thick section and scanning electron microscopy. Cell Tissue Res 288: 317-325, 1997.

20. Hernando N, Gisler SM, Pribanic S, Deliot N, Capuano P, Wagner CA, Moe OW, Biber J, Murer H. NaPi-IIa and interacting partners. $J$ Physiol 567: 21-26, 2005.

21. Hirokawa N. Stirring up development with the heterotrimeric kinesin KIF3. Traffic 1: 29-34, 2000.

22. Hirokawa N, Takemura R. Biochemical and molecular characterization of diseases linked to motor proteins. Trends Biochem Sci 28: 558-565, 2003.

23. Hryciw DH, Ekberg J, Ferguson C, Lee A, Wang D, Parton RG, Pollock CA, Yun CC, Poronnik P. Regulation of albumin endocytosis by PSD95/D1g/ZO-1 (PDZ) scaffolds. Interaction of $\mathrm{Na}^{+}-\mathrm{H}^{+}$exchange regulatory factor-2 with ClC-5. J Biol Chem 281: 16068-16077, 2006.

24. Hryciw DH, Ekberg J, Lee A, Lensink IL, Kumar S, Guggino WB, Cook DI, Pollock CA, Poronnik P. Nedd4-2 functionally interacts with ClC-5: involvement in constitutive albumin endocytosis in proximal tubule cells. J Biol Chem 279: 54996-55007, 2004. 
25. Hryciw DH, Ekberg J, Pollock CA, Poronnik P. ClC-5: a chloride channel with multiple roles in renal tubular albumin uptake. Int J Biochem Cell Biol 38: 1036-1042, 2006.

26. Hryciw DH, Wang Y, Devuyst O, Pollock CA, Poronnik P, Guggino WB. Cofilin interacts with $\mathrm{ClC}-5$ and regulates albumin uptake in proximal tubule cell lines. J Biol Chem 278: 40169-40176, 2003.

27. Jaulin F, Xue X, Rodriguez-Boulan E, Kreitzer G. Polarization-dependent selective transport to the apical membrane by KIF5B in MDCK cells. Dev Cell 13: 511-522, 2007.

28. Jentsch TJ, Hubner CA, Fuhrmann JC. Ion channels: function unravelled by dysfunction. Nat Cell Biol 6: 1039-1047, 2004.

29. John TA, Vogel SM, Minshall RD, Ridge K, Tiruppathi C, Malik AB. Evidence for the role of alveolar epithelial gp60 in active transalveolar albumin transport in the rat lung. $J$ Physiol 533: 547-559, 2001.

30. Jouret F, Bernard A, Hermans C, Dom G, Terryn S, Leal T, Lebecque P, Cassiman JJ, Scholte BJ, de Jonge HR, Courtoy PJ, Devuyst O. Cystic fibrosis is associated with a defect in apical receptor-mediated endocytosis in mouse and human kidney. J Am Soc Nephrol 18: 707-718, 2007.

31. Jouret F, Igarashi T, Gofflot F, Wilson PD, Karet FE, Thakker RV, Devuyst O. Comparative ontogeny, processing, and segmental distribution of the renal chloride channel, ClC-5. Kidney Int 65: 198-208, 2004.

32. Kasper D, Planells-Cases R, Fuhrmann JC, Scheel O, Zeitz O, Ruether K, Schmitt A, Poet M, Steinfeld R, Schweizer M, Kornak U, Jentsch TJ. Loss of the chloride channel ClC-7 leads to lysosomal storage disease and neurodegeneration. EMBO J 24: 1079-1091, 2005.

33. Kottgen M, Benzing T, Simmen T, Tauber R, Buchholz B, Feliciangeli S, Huber TB, Schermer B, Kramer-Zucker A, Hopker K, Simmen KC, Tschucke CC, Sandford R, Kim E, Thomas G, Walz G. Trafficking of TRPP2 by PACS proteins represents a novel mechanism of ion channel regulation. EMBO J 24: 705-716, 2005.

34. Kozyraki R, Fyfe J, Verroust PJ, Jacobsen C, Dautry-Varsat A, Gburek J, Willnow TE, Christensen EI, Moestrup SK. Megalindependent cubilin-mediated endocytosis is a major pathway for the apical uptake of transferrin in polarized epithelia. Proc Natl Acad Sci USA 98: 12491-12496, 2001.

35. Lawrence CJ, Dawe RK, Christie KR, Cleveland DW, Dawson SC, Endow SA, Goldstein LS, Goodson HV, Hirokawa N, Howard J, Malmberg RL, McIntosh JR, Miki H, Mitchison TJ, Okada Y, Reddy AS, Saxton WM, Schliwa M, Scholey JM, Vale RD, Walczak CE, Wordeman L. A standardized kinesin nomenclature. J Cell Biol 167: 19-22, 2004.

36. Lee IH, Campbell CR, Song SH, Day ML, Kumar S, Cook DI, Dinudom A. The activity of the epithelial sodium channels is regulated by caveolin-1 via a Nedd4-2-dependent mechanism. J Biol Chem 284: 12663-12669, 2009.

37. Lloyd SE, Pearce SH, Fisher SE, Steinmeyer K, Schwappach B, Scheinman SJ, Harding B, Bolino A, Devoto M, Goodyer P, Rigden SP, Wrong O, Jentsch TJ, Craig IW, Thakker RV. A common molecular basis for three inherited kidney stone diseases. Nature 379: 445-449, 1996.

38. Minshall RD, Tiruppathi C, Vogel SM, Niles WD, Gilchrist A, Hamm HE, Malik AB. Endothelial cell surface gp60 activates vesicle formation and trafficking via G(i)-coupled Src kinase signaling pathway. J Cell Biol 150: 1057-1070, 2000.

39. Mohammad-Panah R, Ackerley C, Rommens J, Choudhury M, Wang Y, Bear CE. The chloride channel ClC-4 colocalizes with cystic fibrosis transmembrane conductance regulator and may mediate chloride flux across the apical membrane of intestinal epithelia. J Biol Chem 277: 566-574, 2002.

40. Mohammad-Panah R, Harrison R, Dhani S, Ackerley C, Huan LJ, Wang Y, Bear CE. The chloride channel ClC-4 contributes to endosomal acidification and trafficking. J Biol Chem 278: 29267-29277, 2003.

41. Mundy DI, Machleidt T, Ying YS, Anderson RG, Bloom GS. Dual control of caveolar membrane traffic by microtubules and the actin cytoskeleton. J Cell Sci 115: 4327-4339, 2002.

42. Nesbit MA, Bowl MR, Harding B, Ali A, Ayala A, Crowe C, Dobbie A, Hampson G, Holdaway I, Levine MA, McWilliams R, Rigden S, Sampson J, Williams AJ, Thakker RV. Characterization of GATA3 mutations in the hypoparathyroidism, deafness, and renal dysplasia (HDR) syndrome. J Biol Chem 279: 22624-22634, 2004.
43. Nishimura T, Kato K, Yamaguchi T, Fukata Y, Ohno S, Kaibuchi K. Role of the PAR-3-KIF3 complex in the establishment of neuronal polarity. Nat Cell Biol 6: 328-334, 2004.

44. Pfaffl MW. A new mathematical model for relative quantification in real-time RT-PCR. Nucleic Acids Res 29: e45, 2001.

45. Picollo A, Pusch M. Chloride/proton antiporter activity of mammalian CLC proteins ClC-4 and ClC-5. Nature 436: 420-423, 2005.

46. Pirozzi G, McConnell SJ, Uveges AJ, Carter JM, Sparks AB, Kay BK, Fowlkes DM. Identification of novel human WW domain-containing proteins by cloning of ligand targets. J Biol Chem 272: 14611-14616, 1997.

47. Piwon N, Gunther W, Schwake M, Bosl MR, Jentsch TJ. ClC-5 $\mathrm{Cl}^{-}$ channel disruption impairs endocytosis in a mouse model for Dent's disease. Nature 408: 369-373, 2000.

48. Scheel O, Zdebik AA, Lourdel S, Jentsch TJ. Voltage-dependent electrogenic chloride/proton exchange by endosomal CLC proteins. $\mathrm{Na}$ ture 436: 424-427, 2005.

49. Schwake M, Friedrich T, Jentsch TJ. An internalization signal in ClC-5, an endosomal $\mathrm{Cl}^{-}$channel mutated in dent's disease. J Biol Chem 276: 12049-12054, 2001

50. Schwoebel ED, Ho TH, Moore MS. The mechanism of inhibition of Ran-dependent nuclear transport by cellular ATP depletion. J Cell Biol 157: 963-974, 2002.

51. Terryn S, Jouret F, Vandenabeele F, Smolders I, Moreels M, Devuyst O, Steels P, Van Kerkhove E. A primary culture of mouse proximal tubular cells, established on collagen-coated membranes. Am J Physiol Renal Physiol 293: F476-F485, 2007.

52. Tyteca D, Van Der Smissen P, Mettlen M, Van Bambeke F, Tulkens PM, Mingeot-Leclercq MP, Courtoy PJ. Azithromycin, a lysosomotropic antibiotic, has distinct effects on fluid-phase and receptor-mediated endocytosis, but does not impair phagocytosis in J774 macrophages. Exp Cell Res 281: 86-100, 2002.

53. Verkade P, Harder T, Lafont F, Simons K. Induction of caveolae in the apical plasma membrane of Madin-Darby canine kidney cells. J Cell Biol 148: 727-739, 2000.

54. Verroust PJ, Birn H, Nielsen R, Kozyraki R, Christensen EI. The tandem endocytic receptors megalin and cubilin are important proteins in renal pathology. Kidney Int 62: 745-756, 2002.

55. Wang SS, Devuyst O, Courtoy PJ, Wang XT, Wang H, Wang Y, Thakker RV, Guggino S, Guggino WB. Mice lacking renal chloride channel, CLC-5, are a model for Dent's disease, a nephrolithiasis disorder associated with defective receptor-mediated endocytosis. Hum Mol Genet 9: 2937-2945, 2000

56. Wang Y, Cai H, Cebotaru L, Hryciw DH, Weinman EJ, Donowitz M, Guggino SE, Guggino WB. ClC-5: role in endocytosis in the proximal tubule. Am J Physiol Renal Physiol 289: F850-F862, 2005.

57. Wright J, Morales MM, Sousa-Menzes J, Ornellas D, Sipes J, Cui Y, Cui I, Hulamm P, Cebotaru V, Cebotaru L, Guggino WB, Guggino SE. Transcriptional adaptation to Clcn5 knockout in proximal tubules of mouse kidney. Physiol Genomics 33: 341-354, 2008.

58. Wu F, Roche P, Christie PT, Loh NY, Reed AA, Esnouf RM, Thakker RV. Modeling study of human renal chloride channel (hCLC-5) mutations suggests a structural-functional relationship. Kidney Int 63: 1426-1432, 2003.

59. Wu Y, Dai XQ, Li Q, Chen CX, Mai W, Hussain Z, Long W, Montalbetti N, Li G, Glynne R, Wang S, Cantiello HF, Wu G, Chen XZ. Kinesin-2 mediates physical and functional interactions between polycystin-2 and fibrocystin. Hum Mol Genet 15: 3280-3292, 2006.

60. Yamazaki H, Nakata T, Okada Y, Hirokawa N. Cloning and characterization of KAP3: a novel kinesin superfamily-associated protein of KIF3A/3B. Proc Natl Acad Sci USA 93: 8443-8448, 1996.

61. Yamazaki H, Nakata T, Okada Y, Hirokawa N. KIF3A/B: a heterodimeric kinesin superfamily protein that works as a microtubule plus end-directed motor for membrane organelle transport. J Cell Biol 130: $1387-1399,1995$.

62. Zhai XY, Nielsen R, Birn H, Drumm K, Mildenberger S, Freudinger R, Moestrup SK, Verroust PJ, Christensen EI, Gekle M. Cubilin- and megalin-mediated uptake of albumin in cultured proximal tubule cells of opossum kidney. Kidney Int 58: 1523-1533, 2000. 